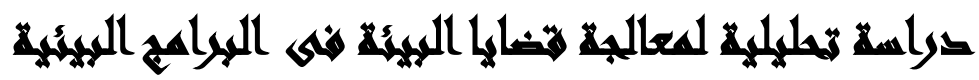

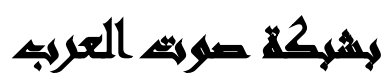

\section{[17]}

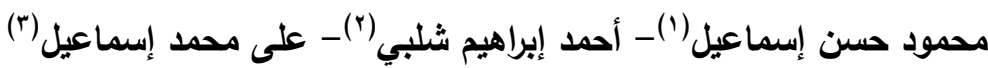

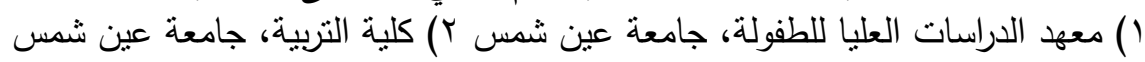

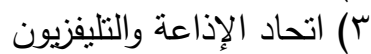

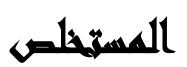

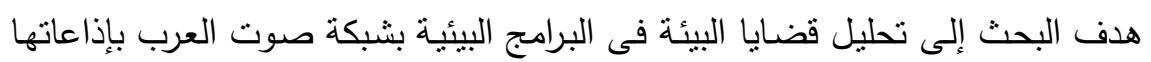

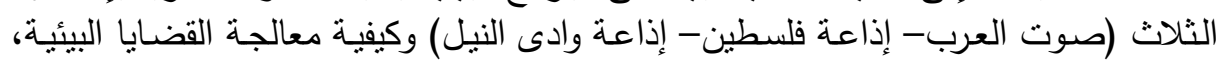

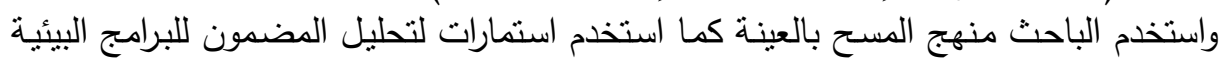

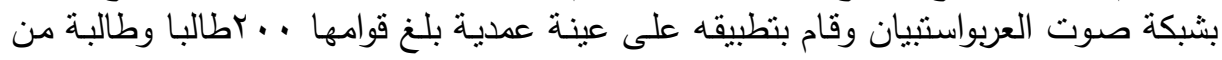

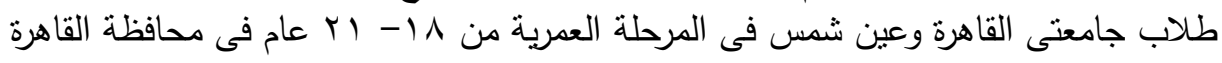

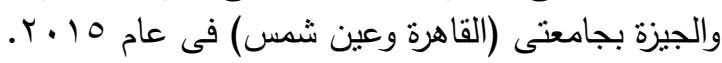

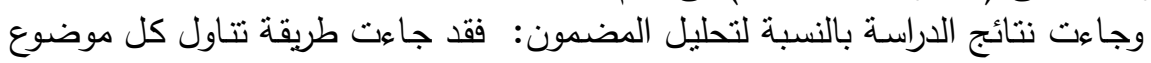

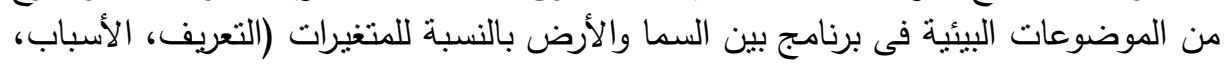

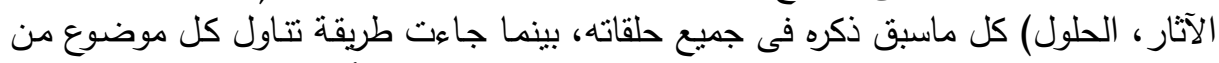

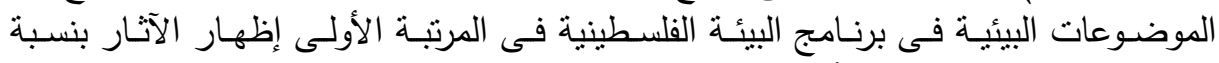

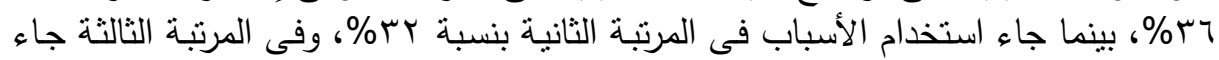

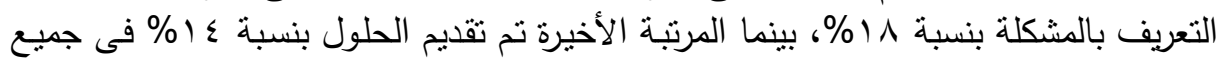

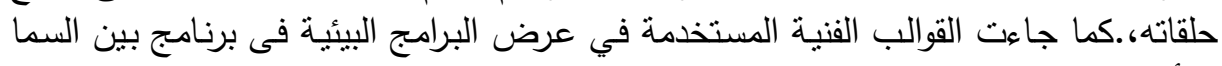

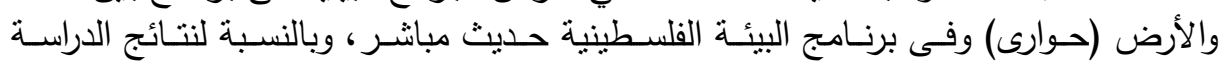

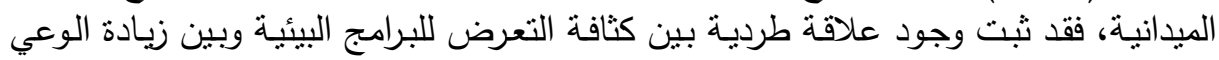

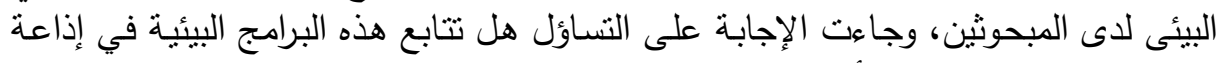

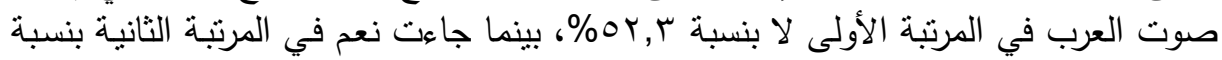

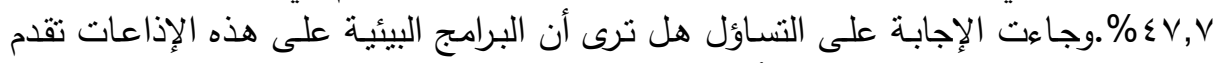

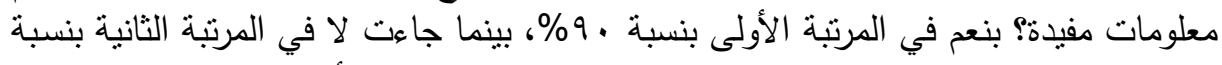

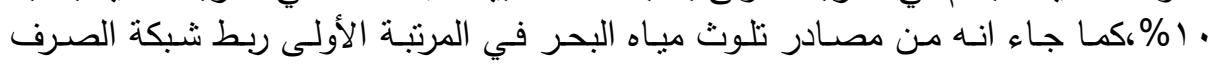

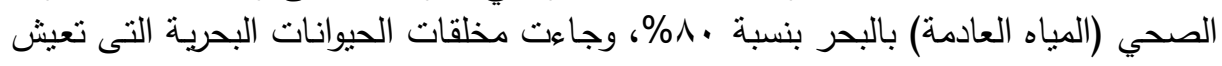

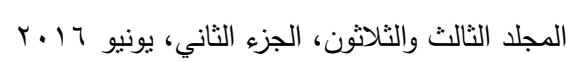




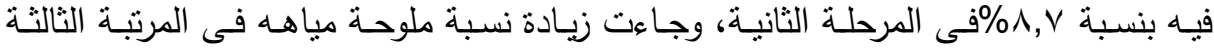

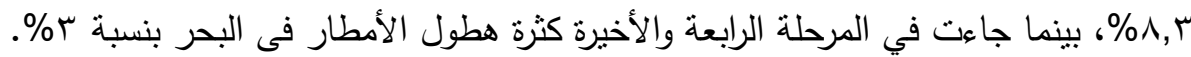

\section{Ras}

مر الإنسان بمراحل تطور مختلفة حتى وصل إلى ماهو علنه اليوم من الرقى والتقدم، الاان ذلك ارتبط فى أحيان كثيرة بالربح الآني الذى أخل بتوازن البيئة واستنزف مواردها إلى الى الى الى

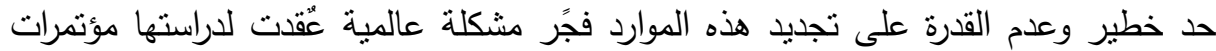
عده منذ السبعينيات، وصدرت على اثرها تشريعات والانظمة لصون البيئة وحمايتها وتحسينها عن طريق اللجوء إلى عملية تربوية تعمل على تقويم السلوك البشرى لجميع الناس، وبناء

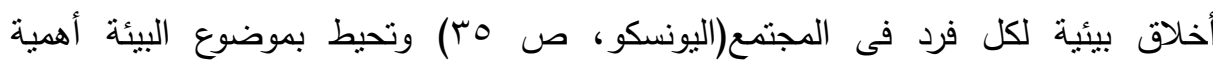
خاصة،لأن موضوع البيئة هو موضوع الحياة على هذا الكوكب فى صورتها الطبيعية والبشرية، ومستوى العلاقة بين البيئيين ونوع هذه العلاقة هما اللذان أعطيا للحياة معناها الحضاري، بدات المشكلة فعليا حين سعى الانسان إلى السبطرة على معطيات الطبيعة وتخطى العلاقة الحوارية التعاونية بينهما (محي الدين صابر،صج) وامعن فى استغلال البيئة من حوله بطريقة غير مدروسة ودون اعتبار للتوازن البيئي، ودون مراعاة لحاجات كائنات اله الاخرى التى تشاركه العيش على هذه الارض وأدى هذا العدوان إلى تلوث البيئة الطبيعية فى البر والبحر والهواء بحيث افسد قدرة الانظمة البيئية على التجدد الثقافى، واخل بالتوازن

$$
\text { الطبيعي لهذه الانظمة (محمد الغولات، صناء بحن). }
$$

إن انتصارات الإنسان اللاهثة السابقة على الطبيعة لم تكن فى صالحة الحة على المدى البعيد وإن حقق فوائد كثيرة على المدى القصير ( جيهان رشتى،صى إنى () ولعبت وسائل الإعلام دوراً كبيراً في تقوية اهتمام الجماهير بقضايا البيئة. ولقد تتبه العالم بمختلف اتجاهاته إلى خطورة ما أصاب البيئة من تردى منذ السبعينيات

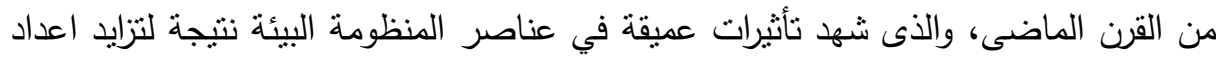

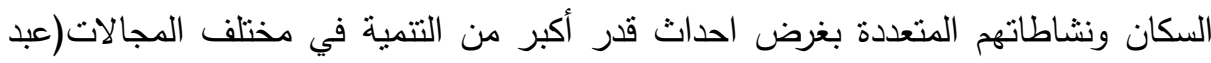

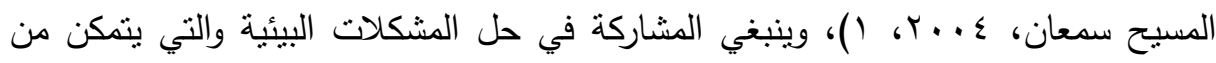


خلالها الأفراد والجماعات بتتمية شعورهم بالمسئولية والإحساس بأن المشكلات البيئية تتسم بطابع العمل بروح الفريق والمشاركة الجماعية في حلها، وما تؤكده لنا من غاية التربية البيئية، والتي تسعى إلى نطوير عالم سكانه أكثر إحساساً واهتماماً بالبيئة ومشكلاتها ويمتلكون

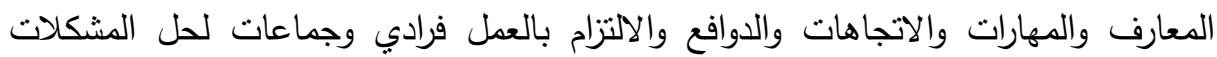

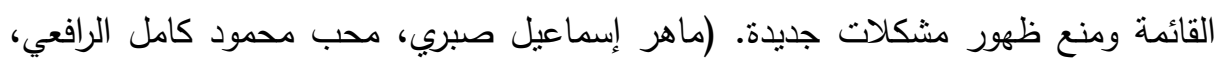
$(r V$, r...r

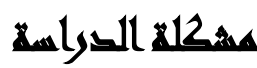

قام الباحث باجراء دراسة استطلاعية على عينة عشوائية بسيطة قوامها أربعون مفردة من

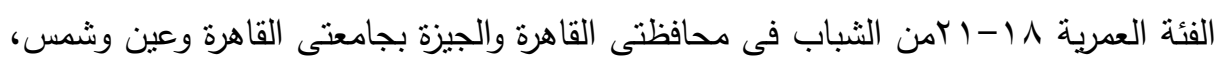

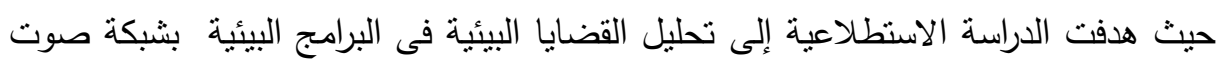

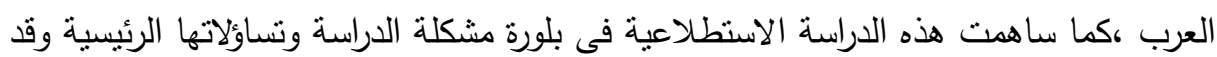
أوضحت هذه الدراسة بوجود عدد من المشكلات البيئية.

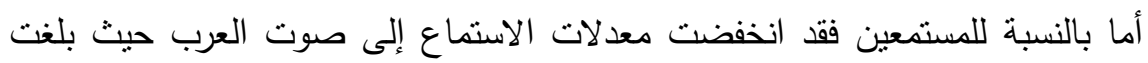

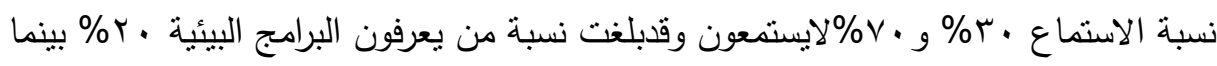

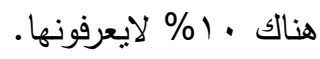

\section{أسئلا الترواسلا}

السؤال الرئيس: ما مدى مساهمة البرامج البيئية بشبكة صوت العرب فى تنمية

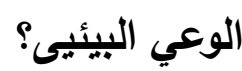

( ) ) تساؤلات خاصة بالدراسة التحليلية:

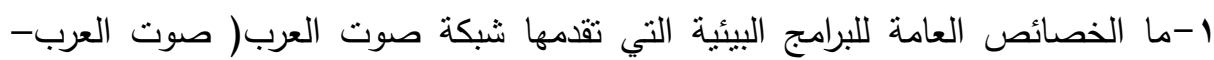

$$
\text { إذاعة فلسطين) }
$$

ץ- ما نوعية المضامين البيئية المقدمة من خلال برامج شبكة صوت العرب؟

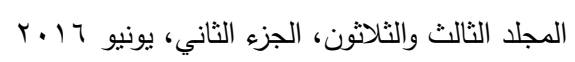




$$
\begin{aligned}
& \text { r-ما القضايا والمشكلات البيئية الأكثر تكراراً فى برامج شبكة صوت العرب؟ }
\end{aligned}
$$

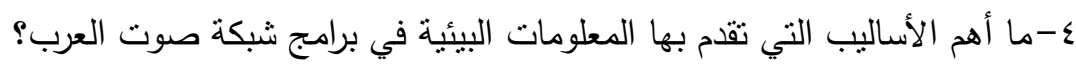

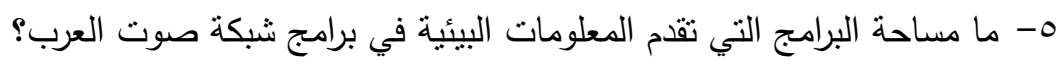

$$
\begin{aligned}
& \text { تساؤلات خاصة بالاراسة الميدانية: }
\end{aligned}
$$

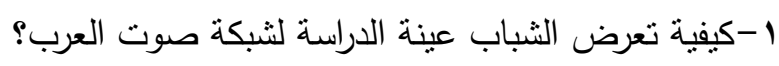

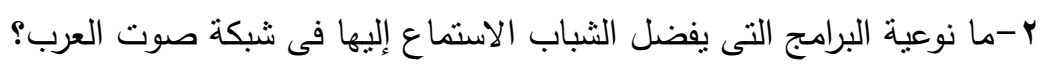

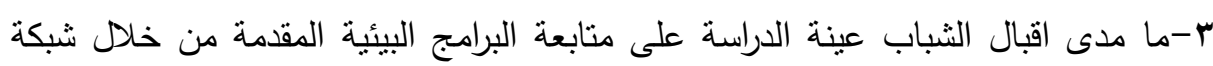

$$
\text { صوت العرب؟ مداب أباب }
$$

ع-ما الأسباب وراء استماع الثباب عينة الدراسة للبرامج البيئية المقدمة في شبكة صوت

$$
\text { العرب؟ }
$$

0- ما أسباب عدم استماع الثباب عينة الدراسة للبرامج البيئية المقدمة في شبكة صوت

$$
\text { العرب؟ }
$$

7-ما مدى تأثثر متغيرات النوع على مستوى المعلومات البيئية لدى شباب الجامعات

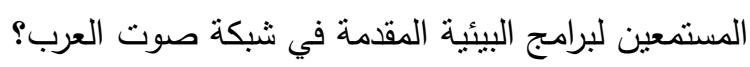

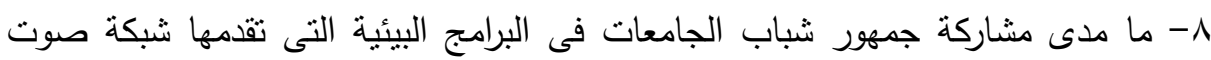

$$
\text { العرب؟ }
$$

9-ما مدى نجاح شبكة صوت العرب فى تقديم معلومات بيئية عن أهم القضايا التى تهم

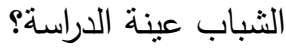

• ا-ما مقترحات الثباب عينة الدراسة لتحسين أداء الخدمة البرامجية فى شبكة صوت

$$
\text { العرب؟ }
$$

\section{أهمه التبرواسمة}

تكتسب هذه الدراسة أهميتها من خلال على النقاط التالية: 1-أهمية الإذاعة كوسيلة اعلامية متميزة من حيث درجة التعرض لمضامينها الاعلامية، وتأكيد الباحثين على نأثيراتها فى مختلف جوانب الفرد المعرفية والوجدانية والسلوكية. 
r-أهية الإعلام فى تتكيل المعرفة لدى الثباب حيث أثبت الأبحاث أن اكثر التوجيهات والآراء الجديدة للمراهقين يكتسبونها من خلال المعلومات التى يحصلون علنها من وسائل الاعلام وفى مقدمتها التليفزيون والراديو .

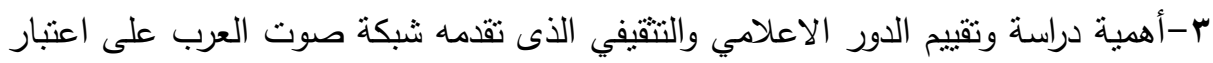
أن نجاح وسائل الإعلام فى تحقيق هذا الدور، هو أحد مقومات بناء وتطور المجتمع حاليًا ومسنقبلاً. ـ -أهمية فئة الجمهور المستهدفة بالدراسة، وهم طلاب الجامعات فى مرحلة المراهقة المتأخرة

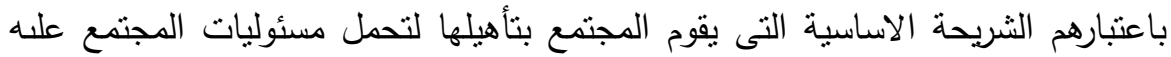
تبنى طموحات مستقبله.

ه-ظهور العديد من المشكلات البيئية والمناخية ممايوسع الاهتمام بدراسة المسئولية البيئية.

\section{أهدا اهن الكواسم}

تسعى هذه الدراسة إلى تحليل قضايا البيئة فى البرامج البيئية بشبكة صوت العرب

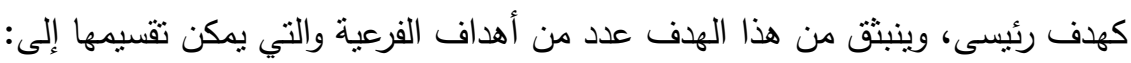

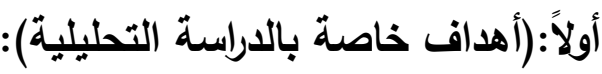
1-التعرف على أهم الأشكال البرامجية التى تقدم المعلومات البيئية فى شبكة صوت العرب

$$
\text { (صوت العرب- إذاعة فلسطين). }
$$

r-التعرف على مساحة البرامج والنشرات التى تقدم المعلومات البيئية فى شبكة صوت البرات

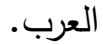

ثانياً: (أهداف خاصة بالاراسة الميدانية ): 1. التعرف على مستوى اهتمام الثباب بالاستماع إلى شبكة صوت العرب (صوت العرب -

$$
\text { إذاعة فلسطين) وحجم تعرضهم لها. }
$$

r. التعرف على الأساليب التى التي تجتذب الثباب لمتابعة البرامج البيئية التي تقدمها شبكة

$$
\text { صوت العرب (صوت العرب- إذاعة فلسطين). }
$$

$$
\text { المجلا الثالث والثلاثثو، الجزء الثاني، يونيو } 17 \text { ـ }
$$


r. التعرف على طبيعة البرامج التي يفضل الثباب متابعتها فى شبكة صوت العرب (صوت العرب-إذاعة فلسطين).

ـ. التعرف على نوعية الموضوعات التى ينم تتاولها فى البرامج البيئية المقدمة من خلال شبكة صوت العرب(صوت العرب- إذاعة فلسطين).

\section{مضور الصراسلا}

$$
\text { الحدود الزمنية حدود الدراسة إلى: }
$$

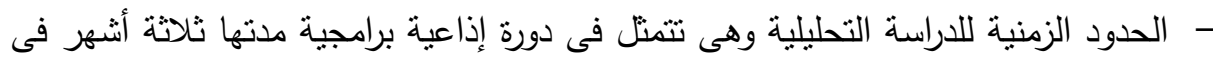

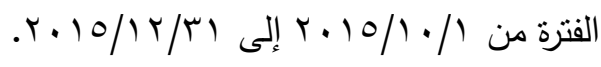

- الحدود الزمنية للدراسة الميدانية فى عام 10 ـ ب وهي تلآلك الفترة التى تم إجراء الاستبيان

الحدود المكانية: حدد الباحث الحدود المكانية للاراسة على عينة عدية فى المرحلة العمرية من 11 - IY إم فى محافظة القاهرة والجيزة بجامعتى (القاهرة وعين شمس) حيث تم اختيار · . اطالب وطالبة من كليات الاعلام وسياسة والاقتصاد والتجارة من جامعة القاهرة

$$
\text { و ، · اطالب وطالبة من كليات الألسن والتجارة والصبيلة. }
$$

\section{الصراسايت المايهي}

ا-دراسة محب محمود الرافعي( · . . . (ف): (فعالية الألعاب التعليمية في تتمية الوعي

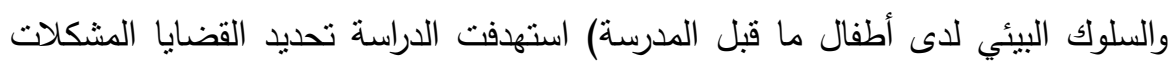
البيئية المناسبة لأطفال ما قبل المدرسة التي تتتاولها الألعاب التعلنية ويمكن من خلالها

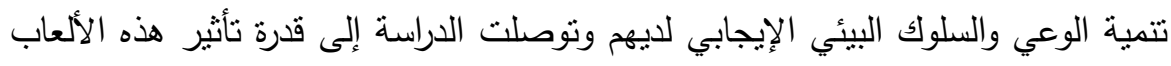

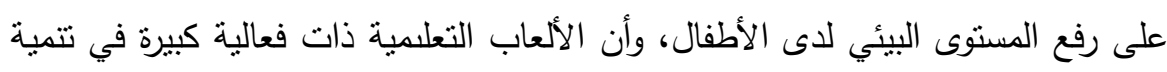

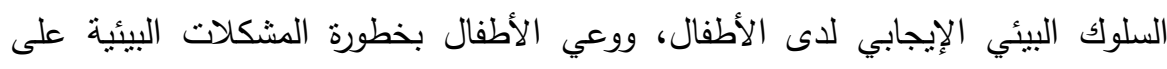

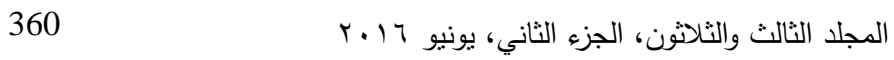


الإنسان والبيئة كان له أثزه في السلوك البيئي الإيجابي لديهم على مستوى الوعى البيئى

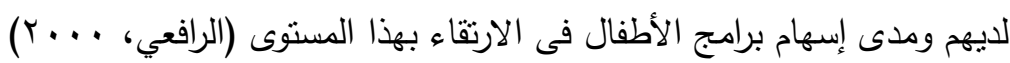
وأهم ما توصلت إليه الاراسة من نتائج: - لا تتتاسب جرعة المضمون البيئى المقدم منه أهمية المتزايدة للمشكلة البيئية فالساحة الممنوحة لها فى برامج الأطفال لا نزال ضعيفة حيث منتل المساحة الزمنية للمضمون البيئى نحو ع, ؟r\% من اجمالى الوقت الفعلى لبرامج الأطفال فى الراديو، وفى التليفزيون

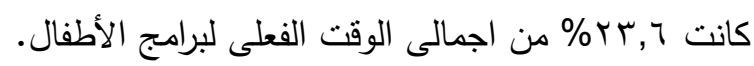

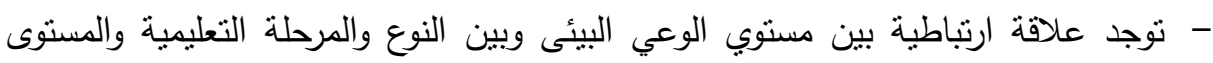
الاقتصادي لصالح الإثاث عن الأكور . - توجد فروق دالة إحصائيا بين مستوي الوعي البيئى وبين مفردات العينة الذين يحصلون على معلوماتهم من المدرسة فقط وبين يحصلون على معلوماتهم البيئية من برامج الأطفال لصالح الأطفال المتابعين لبرامج الأطفال.

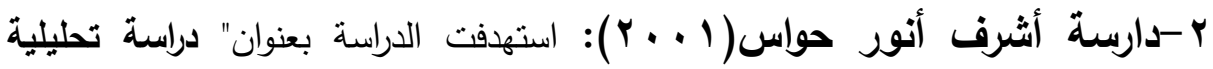

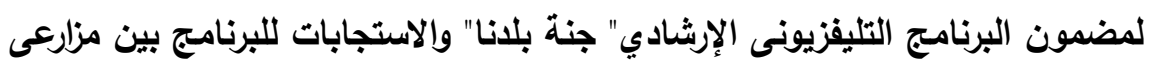

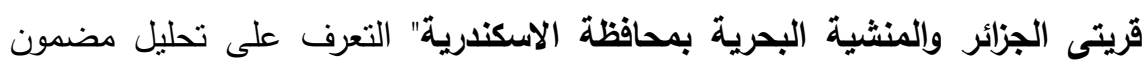

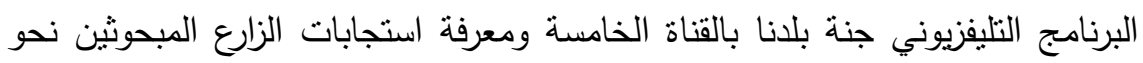

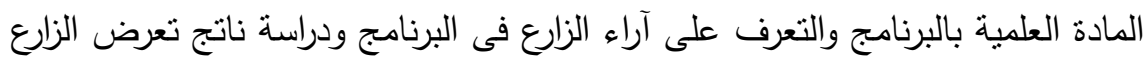
المبحوثين للبرنامج. وقام الباحث بتطبيق دراسة ميدانية باستخدام الاستبيان بالمقابلة الثخصية على 10V

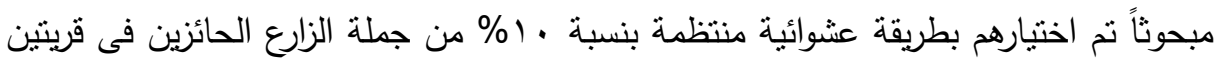
تم اختيارهم بطريقة عشوائية فقد بلغ عدد الزارع المبحوثين فى قرية المنشأة البحرية ل. 1. مبحوث وفى قرية الجزائر OV مبحوثاً. 
وأهم ما توصلت إليه الدراسة من نتائج ما يلى:

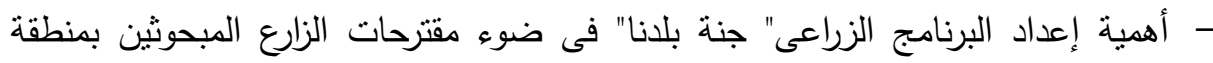
الدراسة لسد احتياجات الزراع واشباع رغباتهم من حيث موعد البرنامج ومدته وترتيب لرني عرض الفقرات وإشراك المزارعين فى فقرات البرنامج.

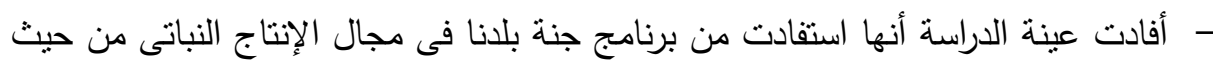
تطبيقهم عمليا لكيفية استعمال المبيدات، وفى مجال الإنتاج الحيوانى من حيث تطبيقهم عمليا لفحص الحيوانات قبل الثراء، وفى مجال تتمية وتطوير المجتمع حيث أفادت غالبية

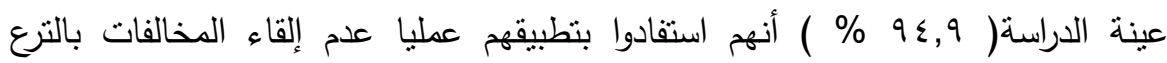
والمصارف.

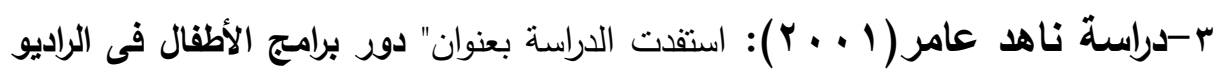
والتليفزيون فى نشر الوعى البيئى لاى الأطفال فى مصر" التعرف على دور تللك البرامج

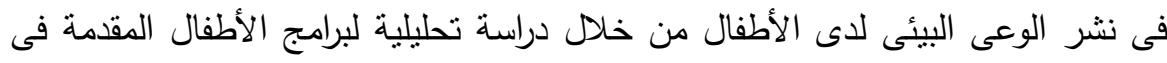
الراديو و التليفزيون. حيث تم إجراء دراسة تحليلية لبرامج الأطفال المقدمة فى الراديو والتليفزيون فى دورة

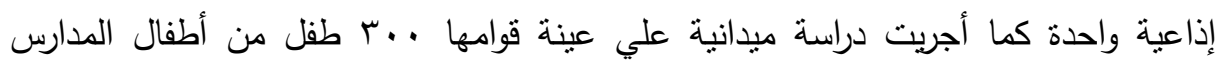

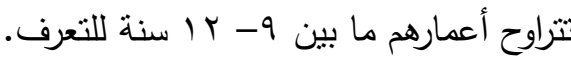

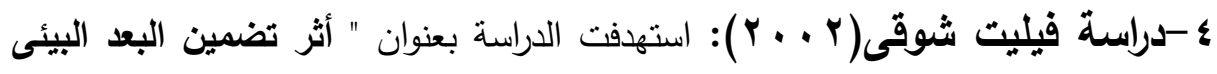

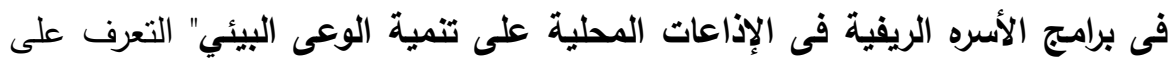

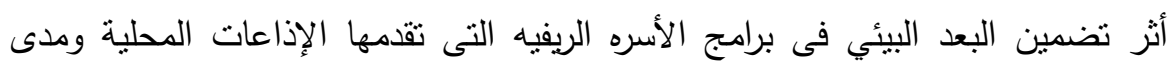

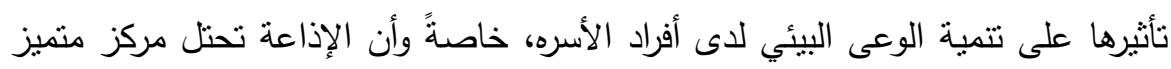

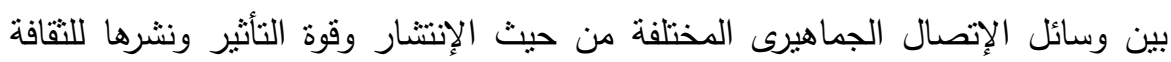
والتوعية. 
واستخدت الباحثة أسلوب تحليل المضمون لبعض برامج الأسره الريفيه فى إذاعة القاهرة

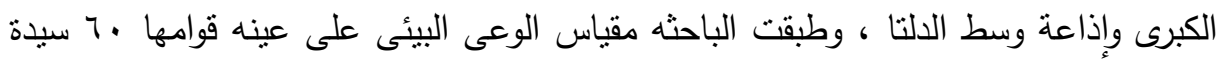
من المنسربات من التعليم والحاصلات على شهادة محو الأمية.

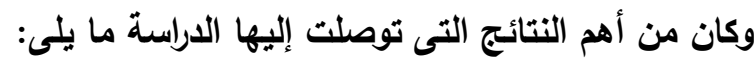
- قلة إهتمام البرامج بالموضوعات البيئيه ومن الموضوعات التى أظهرتها البرامج: المخلفات

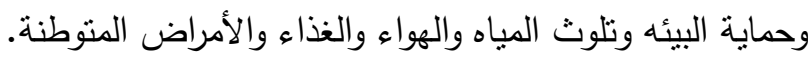
- وجود فروق ذات دلاله إحصائية بين المجموعتين الضابطه والتجريبية بعد تطبيق البرنامج

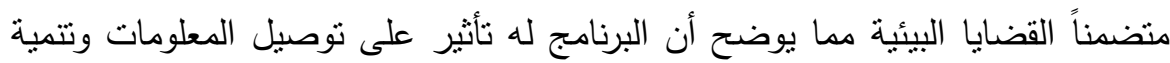

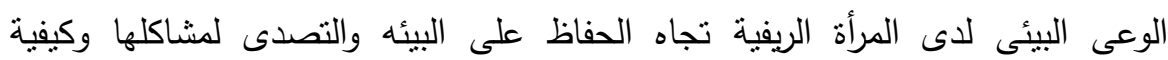
الوصول إلى حلها.

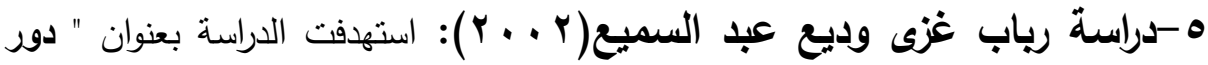
الإعلام فى حماية البيئه الريفية" التعرف على دور وسائل الإعلام فى حماية البيئة الريفية ذلك من خلال تحليل مضمون البرامج الإذاعية والتلفزيونية الزراعية والبيئية والمادة الصحفية المقدمة.

كما استهدفت الدراسة التعرف على بعض الخصائص الثخصية والاجتماعية ومصادر المعلومات لأفراد عينة الدراسه. والتعرف على أثز تعرض السكان الريفين المبحوثين

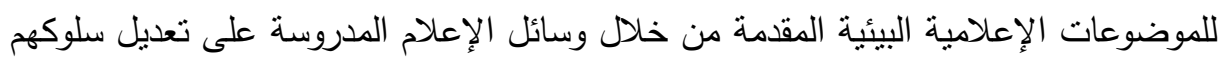
الخاص بحماية البيئه الريفية وقد اقتصرت الدراسه على القناة السادسة ممثلة للتلفزيون وإذاعة فئه وسط الدلتا ممثله للإذاعه وجريدة الأهرام ممنله للصحافة.

تم تطبيق الدراسة على عينة قوامها VYV مبحوث من قرى: ( كفر عصام وبهبيت الحجاره) بمحافظة الغربية، واستخدمت الباحثة مجموعة من الإختبارات الإحصائيه منها

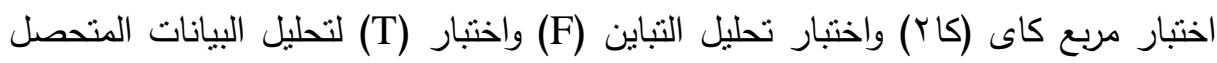




\section{وتوصلت الاراسةةإلى مجموعة من النتائج أهمها:}

- جاء التلفزيون فى المرتبة الأولى بين وسائل الإعلام فيما بتصل بمستوى تعرض المبحوثلئ

$$
\text { اليومي لما يقدمه من مواد إعلامية. }
$$

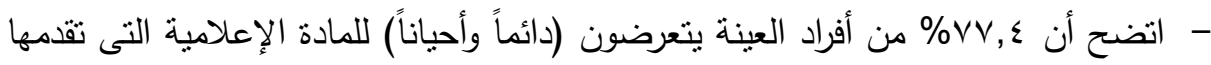

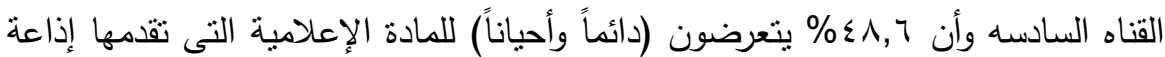

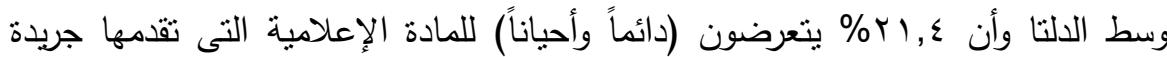

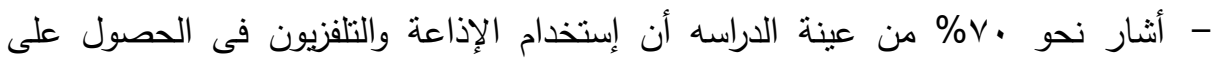
المعلومات يؤثر على تعديل سلوكهم نحو حماية البيئه الريفية.

צ-دراسة زينب إسماعيل(r ץ): استهدفت الدراسة بعنوان " معالجة القضايا البيئيه فى برامج منوعات التلفزيون" التعرف على كيفية معالجة القضايا البيئية فى برامج المنوعات بالقنوات الرئيسية الأولى والثانية وإحدى القنوات المحلية" القناه الثالثة" واستخدت الباحثة المنهج الوصفى عن طريق تحليل المضمون لأربعة برامج على بلى لألى

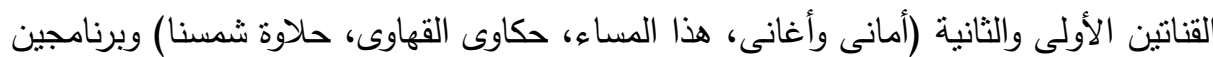
على القناة الثالثة (ما يطلبه المشاهدون، مجلة المنوعات). وتم تطبيق البحث على عينة قوامها ـ10 فرد من مشاهدى البرامج وـ1 10 من القائمين بالإتصال عن طريق الإستبيان. وكان من أهم النتائج التى توصلت لها الدراسه أهمية دور برامج المنوعات فى التلفزيون

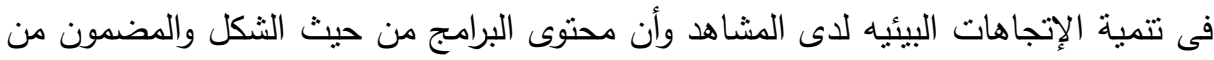
الأسباب العامه فى إقبال المشاهد على مثل هذه البرامج أو إعراضه عنه عنها.

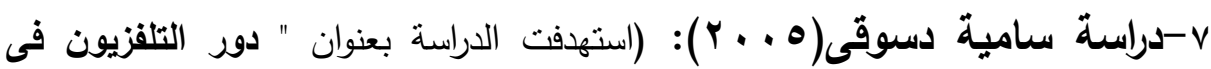
إمداد المرأة المصرية بالمعلومات البيئية" التعرف على دور التلفزيون فى إمداد المرأة

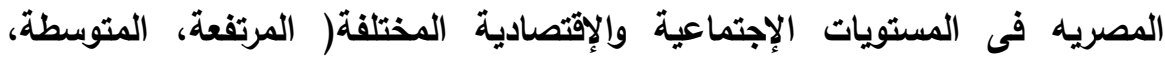
المنخفضة ) بالمعلومات المتعلقة بالقضايا والمشكلات البيئية، وذلك من خلال دراسة 


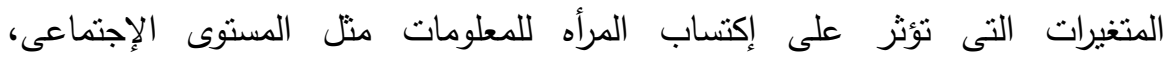

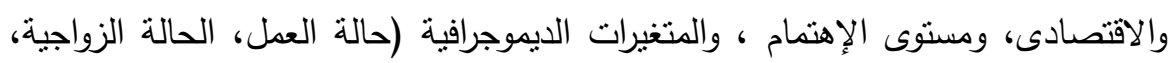

$$
\text { التعليم، السن). }
$$

واستخدمت الباحثة منهج المسح الاجتماعى بالعينة بإستخدام صحيفة الاستقصاء

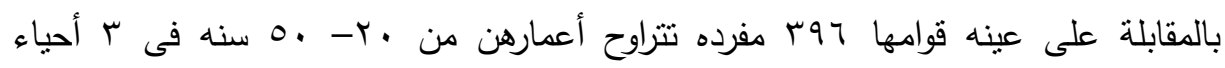
بمحافظة القاهرة هى ( المعادى، منيل، حلوان ).

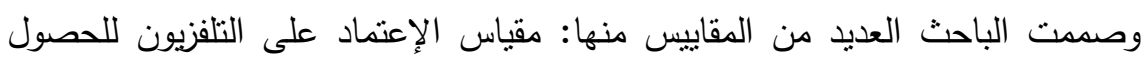
على المعلومات البيئية ومقياس التعرض للبرامج والمواد البيئيه فى التلفزيون.

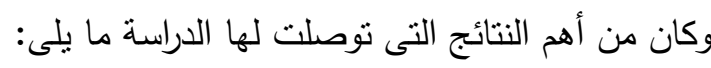
-اعتماد المرأة على التلفزيون كأهم مصدر للمعلومات بصفه توان عامه والمعلومات البيئية بصفه

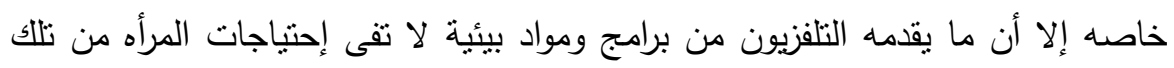

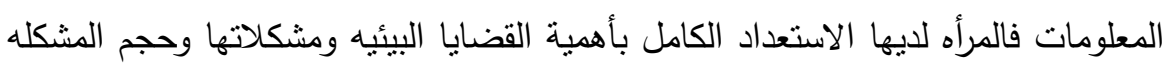

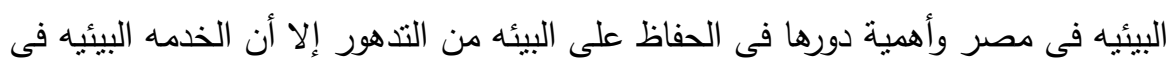
البرامج والمواد التلفزيونيه تحتاج إلى التطوير شكلاً ومضموناً. - أنبتت الدراسة وجود فجوة معرفية بقضايا ومشكلات البيئة بين فئات السيدات المختلفة فى ومئي المستوى الإجتماعى الإقتصادى.

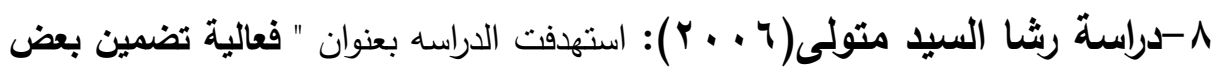

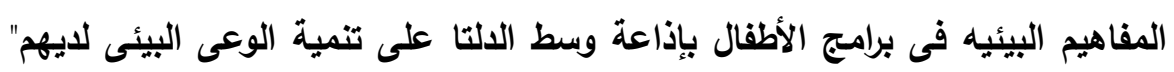

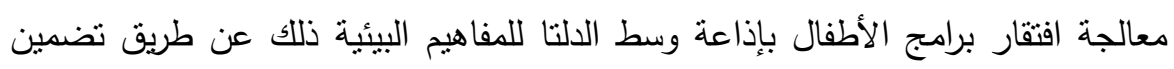

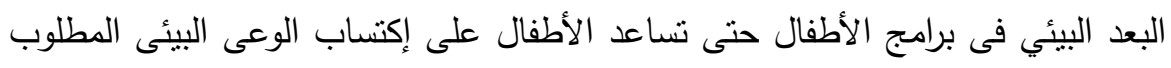


واعتمدت الدراسة على استخدام المنهج الوصفى وذلك لتحليل مضمون برامج الأطفال

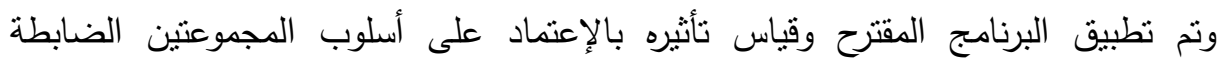
والتجريبيه وتم تطبيق مقياس الوعى البيئي على عينه قوامها . IT مفرده من الأطفال

$$
\begin{aligned}
& \text { المنتظمين فى الصف الخامس الإبتدائى بمدينة طنطا فى سن (• (1 - 11 ) سنة. } \\
& \text { وأهم ما توصلت إليه الاراسة من نتائج: }
\end{aligned}
$$

- المفاهيم البيئية المقدة للأطفال قليله جداً ولا تتتاسب من مع نائه أهمية قضايا البيئة. - إعداد البرامج للأطفال لا يتم على أساس علمي بل معظمها إجتهاديه بدون أسس واضحسه. - قصور برامج الأطفال بإذاعة وسط الدلتا فى معالجة قضايا البيئة.

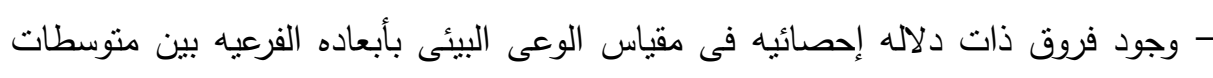

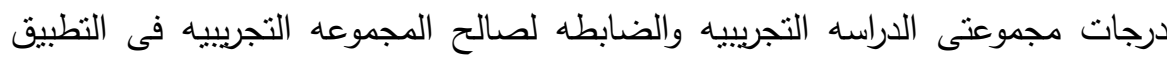
البعدى.

- وجود فروق ذات دلاله إحصائية فى مقياس الوعى البيئى بين بنين وبنات المجموعة

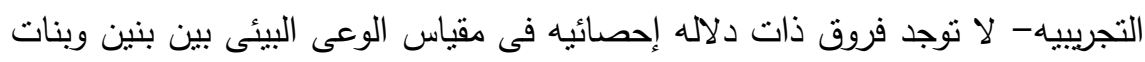
المجموعه التجريبيه فى القياس البعدى.

9- دراسة حمزة بن الزين(ب I • Y): بعنوان: المسؤولية البيئية والاجتماعية للشركات البترولية دراسة حالة مجمع المؤسسة الوطنية لخدمات الآبار (ENSP) بحاسي مسعود خلال فترة مارس ب ا • ب: هدفت الدراسة إلى بحث مدى إمكانية إلتزام المؤسسات

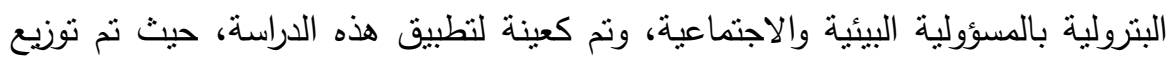

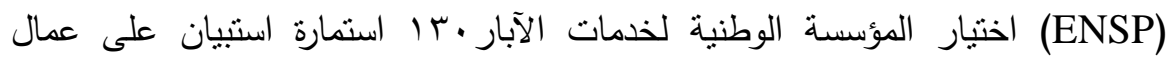

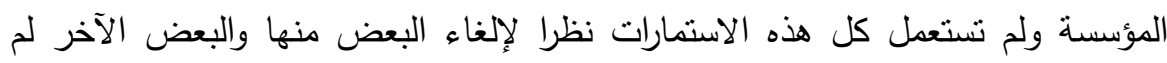

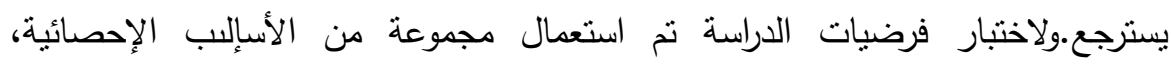
كالمتوسط الحسابي المرجح والانحراف المعياري للوصول إلى نتائج تساعدنا في الحكم على المؤسسة. 
وأهم النتائج التي توصلت لها الدراسة:

ا-رغم تتوع وتعدد الآراء حول مفهوم المسؤولية الاجتماعية من تصنيفها بأنها إلتزام على عاتق الثركات إلى تصنيفها كذللك بأنها استجابة طوعية إلا أنها لا تخرج على على كونها أعمال خيرية هادفة سواء للعمال أو للمجتمع. ץ-أن التقيد والاهنمام بمبادئ وأبعاد المسؤولية البيئية والاجنماعية لا يتنافى مع أهداف وأفاق الثركات البترولية.

r-أن المؤسسة محل الدراسة( المؤسسة الوطنية لخدمات الأبار) لا نطبق أبعاد المسؤولية البيئية والاجتماعية.

\section{التعليق على الدراسات السابقة:}

• • أن هناك معوقات تواجه الإدارة البيئة في الوطن العرب بصفة عامة وهي:

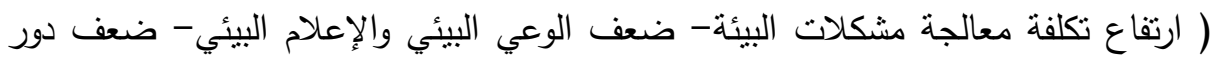

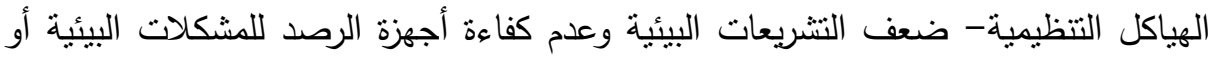
لرصد الأزمات البيئية الطارئة- قصور مصادر التمويل لمعالجة تلك المشكلات).

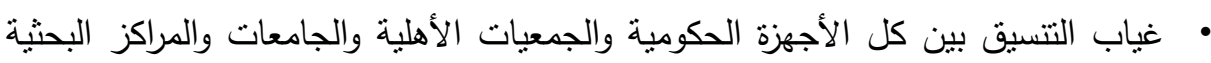
للاستفادة من خبرات كل منهم في الأمور المتعلقة بالبيئة. • عدم وجود عمالة مدربة.

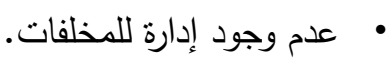

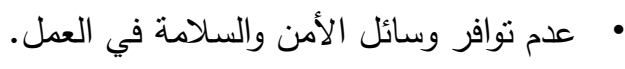
• عدم وجود عمالة مدربة. • عدم وجود إدارة للمخلفات. • • عدم توافر وسائل الأمن والسلامة في العمل. • انخفاض مستوي الوعي.

• أن نطبيق نظم الإدارة البيئة يؤدي إلى تحقيق الرضا الوظيفي وبالتالى تحسين أداء

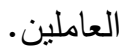




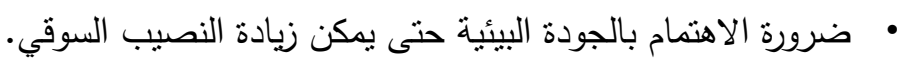
• أن التوسع غير المخطط في المشروعات يؤدي إلى إهدار في الموارد الطبيعية. • • أن تبني الشركات لمفهوم الإدارة البيئية يؤدي إلى تحسين مستوي الأداء. • • أن عملية التدوير يمكن الاستفادة منها لتخفيف الحمل عن البيئة. • • ضرورة توزيع السلطات والمهام حسب حاجة العمل. • أن عدم توافر الاتصالات السليمة داخل المصنع قد تعوق تحسين الأداء البيئي.

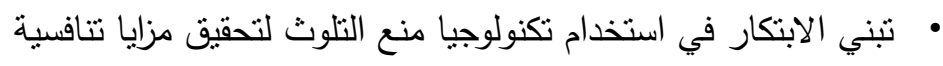
مدى الاستفادة من الاراسات السابقة:

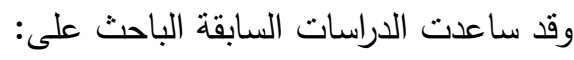
1-تكوين رؤية واضحة نحو المشكلة البحثية من حيث تحديدها وصياغتها. r-صياغة تساؤلات الدراسة بشكل علمي يحقق أهداف الدراسة. r- تحديد المناهج والأسإلبب المستخدمة فى الدراسة. ع-تصميم استمارة تحليل المضمون، ووضع التعريفات الإجرائية لفئات ووحدات التحليل المتعلقة بالدراسة. ه-تصميم استمارة الاستبيان المتعلقة بالدراسة. 7 -تحديد المفاهيم والمصطلحات المستخدمة فى الدراسة. V-تجميع المادة العلية الخاصة بالدراسة بالإطلاع على الأجزاء النظرية للاراسات السابقة

$$
\text { التى تفيد موضوع الدراسة. }
$$

1-تحديد مجتمع البحث وعينة الدراسة.

9-تفسير النتائج حيث استعان الباحث ببعض نتائج الدراسات السابقة قريبة الصلة بدراسة الباحث لاجراء المقارنات للوقوف على أوجه الاتفاق والاختلاف بين نتائج هذه الدراسة

$$
\text { ونتائج الدراسات السابقة. }
$$




\section{مهاهيه السراسمة}

\section{أ-المفاهيم الإجرائية:}

•البرامج البيئية: وهى تلك البرامج الإذاعية التى تهتم بالبيئة وتذاع على شبكة اذاعات صوت العرب.

• شبكة صوت العرب: وتتضمن شبكة صوت العرب (صوت العرب- إذاعة فلسطين- إذاعة

وادي النيل).

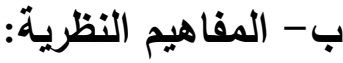

1- البرامج الإذاعية (محمود الرجبي ص r r ) ): عبارة عن مادة إذاعية تبث مسجلة أو حية على الهواء وتشغل مساحة زمنية محددة من ساعات البث الاذاعي لأية محطة إذاعية.

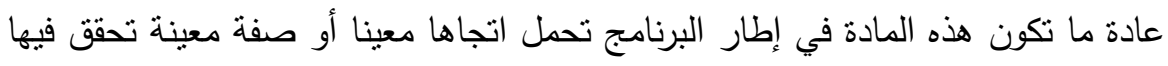

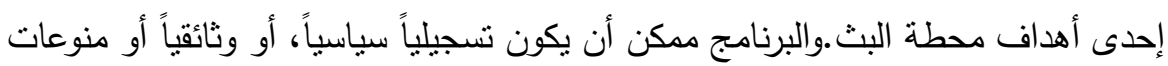

$$
\text { أو ديني أو بيئي وموجه لفئة محددة من المشاهدين أو عموم المشاهدين. }
$$

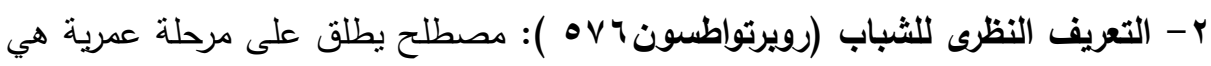

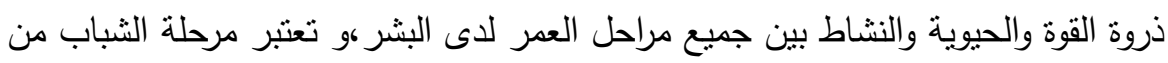
أهم المراحل التي يمر بها الفرد، حيث تبدأ شخصية الإنسان بالتبلور .

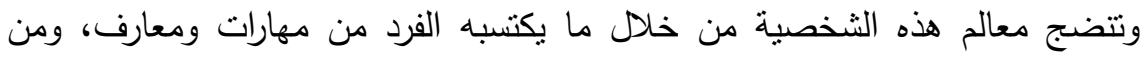
خلال النضوج الجسماني والعقلي، والعلاقات الاجتماعية التي يستطيع الفرد صياغتها ضمن

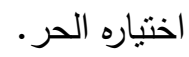

وتحدد الأمم المتحدة تحدد فئة الثباب بأنهم أولئك الذين ثتراوح أعمارهم بين 10 و ـr 


\section{الاجبراءايت المنمجية}

ا-بالنسبة لتحليل المضمون: قام الباحث بعمل استمارات لتحليل المضمون وعرضها

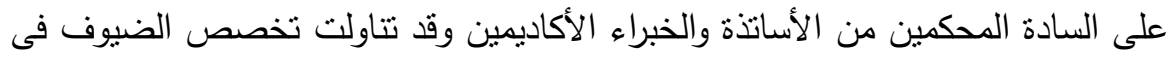

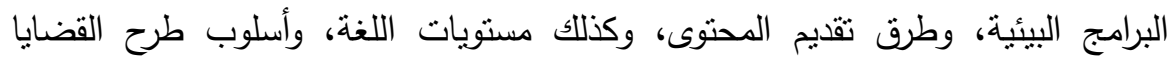

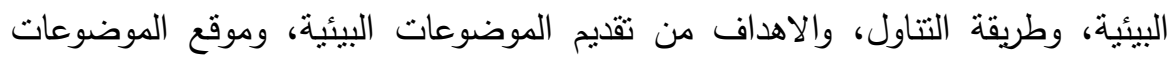

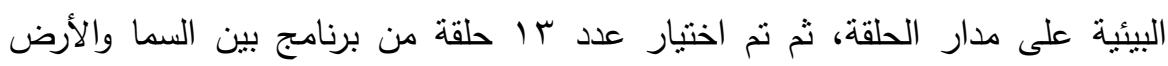

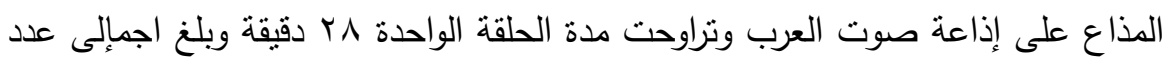

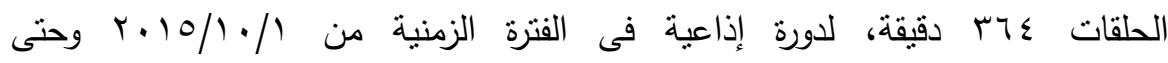

$$
. r \cdot 10 / T / \mu)
$$

بينما تم اختيار عدد \& جلقة من برنامج البيئة الفلسطينية المذاع على إذاعة فلسطين

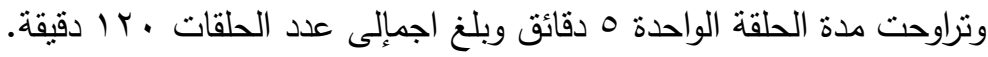

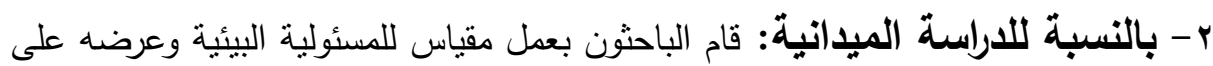
مجموعة من السادة الحكمين من الأساتذة والخبراء الاكاديمين ثم قام بتطبيقه على عينة

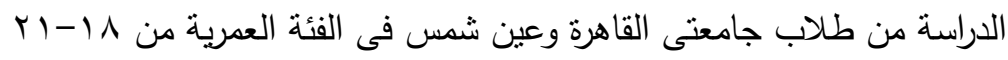

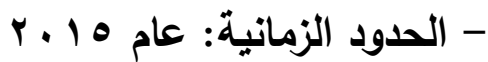
توضح الجداول الآتية عينة الدراسة النحليليلة ونوع مقدم البرامج ومدى الاستعانة بالضيوف من الخبراء والمختصين.

\section{توصيف عينة الدراسة التحليلية:}

\begin{tabular}{|c|c|c|c|c|c|c|}
\hline \multicolumn{2}{|c|}{ الالمدة الزمنية } & \multicolumn{2}{|c|}{ اللمدة الزمنية } & \multirow{2}{*}{ الحلقات } & \multirow{2}{*}{ البرنامج } & \multirow[t]{2}{*}{ الإذاعة } \\
\hline ق & $\dot{\bar{\Xi}}$ & ق & $\dot{\Delta}$ & & & \\
\hline$\overline{r T \varepsilon}$ & - & $r \Lambda$ & - & 14 & بين السما والأرض & صوت العرب \\
\hline IT. & - & 0 & - & $r \varepsilon$ & البيئة الفلسطينية & فلسطين \\
\hline$\varepsilon \wedge \varepsilon$ & - & $r r$ & - & rT & جمَآلى & \\
\hline
\end{tabular}


يوضح الجدول رقم(r) نوع مقدم البرامج:

\begin{tabular}{|c|c|c|c|c|c|}
\hline \multirow{2}{*}{ الاجمالى } & \multicolumn{2}{|c|}{ البيئة الفلسطينية } & \multicolumn{2}{|c|}{ بين السما والأرض } & \multirow{2}{*}{ نوع مقدم البرامج } \\
\hline & $\%$ & ك & $\%$ & 5 & \\
\hline - & - & - & - & - & ذكر \\
\hline$\mu v$ & $\% 1 \ldots$ & $T \xi$ & $\% 1 \ldots$ & $\pi$ & آنتي \\
\hline$r v$ & $\% 1 \ldots$ & $T \xi$ & $\% 1 \ldots$ & $\pi$ & الاجمال \\
\hline
\end{tabular}

- من خلال بيانات الجدول السابق نلاحظ أن:

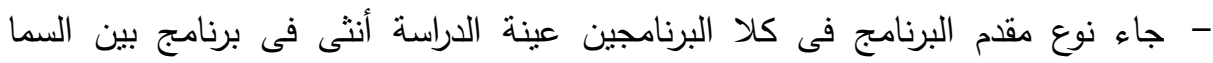
والأرض، وفى برنامج البيئة الفلسطينية.

\section{أهم نمائي القواسمة}

أولاً: الدراسة التحليلية:

جدول رقم(ץ): يوضح مدى الاستعانة بضيوف فى البرامج البيئية

\begin{tabular}{|c|c|c|c|c|}
\hline \multicolumn{2}{|c|}{ البيئهة القلسطينية } & \multicolumn{2}{|c|}{ بين السما والأرض } & \multirow{2}{*}{ الاستعانة بضيوف } \\
\hline$\%$ & ك & $\%$ & ك & \\
\hline$\overline{-1}$ & " - & $\% 1 \ldots$ & $\overline{1 T}$ & استعان \\
\hline$\% 1 \ldots$ & $T \xi$ & - & - & لم بستعن \\
\hline$\% 1 \ldots$ & T\& & $\% 1 \ldots$ & $1 \pi$ & الاجمالى \\
\hline
\end{tabular}

- من خلال بيانات الجدول السابق نلاحظ أن: - برنامج بين السما والأرض استعان بضيوف بنسبة . . 1 \% في جميع حلقاته. - بينما برنامج البيئة الفلسطينية لم يستعن بضيوف إطلاقا خلال حلقاته يوضح جدول رقم(ء) ): تخصص الضيوف فى البرامج البيئية

\begin{tabular}{|c|c|c|c|c|}
\hline \multicolumn{2}{|c|}{ البيئة القلسطينية } & \multicolumn{2}{|c|}{ بين السما والأرض } & \multirow{2}{*}{ تخصص الضيوف } \\
\hline$\%$ & ك & $\%$ & (5) & \\
\hline$\overline{-1}$ & $\overline{-1}$ & 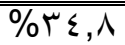 & 17 & آحد آطراف المشكلة آو القضية \\
\hline- & - & $\% r q, r$ & 11 & خبير آو متخصص \\
\hline- & - & \%rฯ, & $\pi$ & مسئول \\
\hline- & - & $\% 1 \ldots$ & $\leqslant 7$ & الاجمالي \\
\hline
\end{tabular}


من خلال بيانات الجدول السابق نلاحظ أن: - جاء تخصص الضيوف فى برنامج بين السما والأرض فى المرنبة الأولى خبير

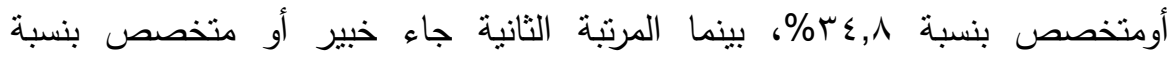

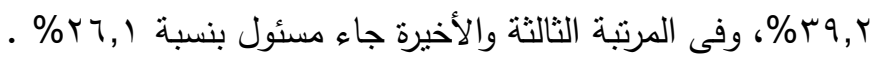
يوضح جلول رقم(•): طرق تقديم المحتوى فى البرامج البيئية:

\begin{tabular}{|c|c|c|c|c|}
\hline \multicolumn{2}{|c|}{ البيئة القلسطينية } & \multicolumn{2}{|c|}{ بين السما والآرض } & \multirow{2}{*}{ طرق تقديم المحتوى } \\
\hline$\%$ & ك & $\%$ & ك & \\
\hline$\%$ & Y & - & - & مادة كلامية \\
\hline- & - & $\% 1 \ldots$ & 14 & مادة كلامية مصحوبة بتقارير \\
\hline$\% 1 \ldots$ & $T \xi$ & $\% 1 \ldots$ & $\pi$ & الاجمالّ \\
\hline
\end{tabular}
من خلال بيانات الجدول السابق نلاحظ أن: - جاءت طرق تقديم المحتوى فى برنامج بين السما والأرض بنسبة . .. 1\% مادة كلامية مصحوبة بتقارير فى جميع حلقاته. - بينما جاءت طرق تقديم المحتوى فى برنامج البيئة الفلسطينية بنسبة . . 1\% مادة كلامية فى جميع حلقاته. يوضح جدول رقم(7): مستويات اللغة المستخدمة فى البرامج البيئية:

\begin{tabular}{|c|c|c|c|c|}
\hline \multicolumn{2}{|c|}{ البيئة القلسطينيةة } & \multicolumn{2}{|c|}{ بين السما والأرض } & \multirow{2}{*}{ مستويات اللغة المستخدمة } \\
\hline$\%$ & ك & $\%$ & ك & \\
\hline$\overline{\% \% \wedge r, r}$ & T. & - & $\overline{-1}$ & فصحى المتثقفين \\
\hline$\% \backslash 7, V$ & $\varepsilon$ & $\% 1 \ldots$ & $\pi$ & عامية المثقفين \\
\hline$\% 1 \ldots$ & $T \xi$ & $\% 1 \ldots$ & $T$ & الاجمالى \\
\hline
\end{tabular}
من خلال بيانات الجدول السابق نلاحظ أن:

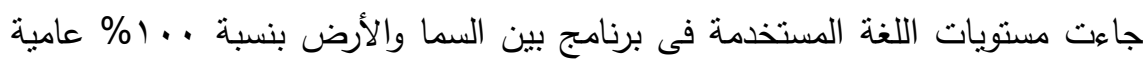
المثقفين فى جميع حلقاته .بينما جاءت مستويات اللغة المستخدمة فى برنامج البيئة الفلسطينية

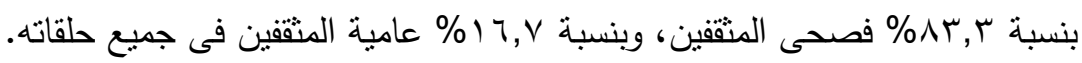


يوضح جدول رقم(V): أسلوب طرح القضية فى البرامج البيئية:

\begin{tabular}{|c|c|c|c|c|}
\hline \multicolumn{2}{|c|}{ البيئة القلسطينية } & \multicolumn{2}{|c|}{ بين السما والآرض } & \multirow{2}{*}{ أسلوب طرح القضية } \\
\hline$\%$ & S & $\%$ & 5 & \\
\hline \%Уo & 111 & $\% \vee \vee 7, q$ & 1. & مباشر \\
\hline$\% \wedge, \Gamma$ & $r$ & $\% \vee, \vee$ & 1 & غير مباشر \\
\hline$\% \backslash 7, V$ & $\varepsilon$ & $\% \backslash 0, 乏$ & $r$ & الاثثان معا \\
\hline$\% 1 \ldots$ & $r \varepsilon$ & $\% 1 \ldots$ & $\pi$ & الاجمالي \\
\hline
\end{tabular}

من خلال بيانات الجدول السابق نلاحظ أن:

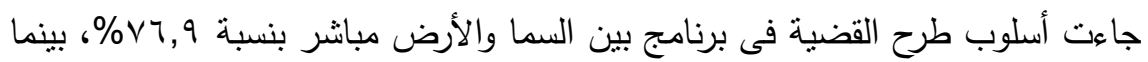

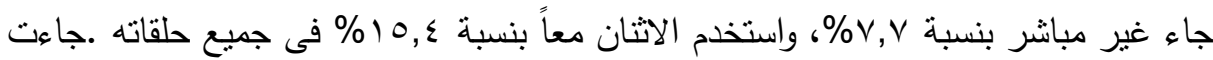

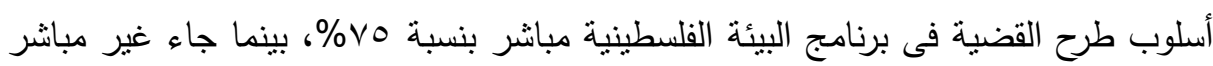

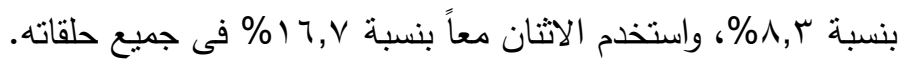
يوضح جدول رقم(^): طريقة تتاول كل موضوع من الموضوعات البيئية:

\begin{tabular}{|c|c|c|c|c|}
\hline \multicolumn{2}{|c|}{ البيئة القلسطينية } & \multicolumn{2}{|c|}{ بين السما والأرض } & \multirow{2}{*}{ طريقة تناول } \\
\hline$\%$ & ك & $\%$ & ك & \\
\hline$\% \backslash \wedge$ & 9 & $\overline{-1}$ & 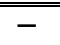 & التعربف \\
\hline \%rr & 17 & - & - & الأسباب \\
\hline \%rт & 11 & - & - & الآثار \\
\hline$\% \backslash \varepsilon$ & $\mathrm{V}$ & - & $\begin{array}{lll}- & & \end{array}$ & الحلول \\
\hline- & - & $\% 1 \ldots$ & Ir & جميع ماسبق \\
\hline$\% 1 \ldots$ & 0. & $\% 1 \ldots$ & IT & الاجمال \\
\hline
\end{tabular}

من خلال بيانات الجدول السابق نلاحظ أنه: جاءت طريقة تتاول كل موضوع من

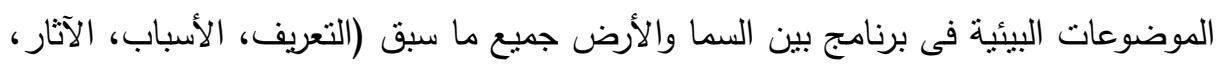

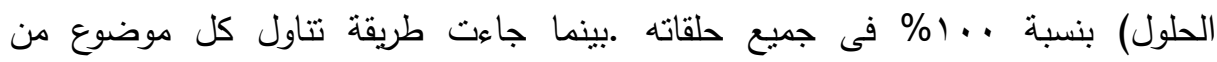
الموضوعات البيئية فى برنامج البيئة الفلسطينية فى المرتبة الأولى إظهار الآثار بنسبة

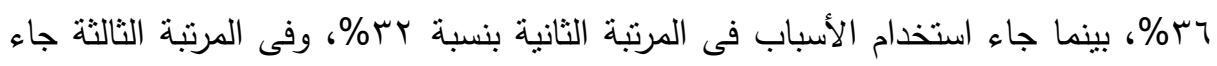

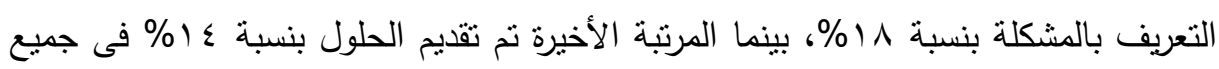
حلقاته. 
يوضح جدول رقم(9): الهدف المرجو من تقديم الموضوعات البيئية:

\begin{tabular}{|c|c|c|c|c|}
\hline \multicolumn{2}{|c|}{ البيئة الفلسطينية } & \multicolumn{2}{|c|}{ بين السما والأرض } & \multirow{2}{*}{ الهذف المرجو } \\
\hline$\%$ & ك & $\%$ & ك & \\
\hline$\% \backslash 7, V$ & $\varepsilon$ & \%rr,l & $\bar{r}$ & هدف اعلام, \\
\hline \%тr,o & 10 & $\% 79, Y$ & $\overline{9}$ & هدف توجيهي ارشادى \\
\hline$\%$ \%r, $\wedge$ & 0 & $\% \vee, \vee$ & $T$ & هدف تعلنمي \\
\hline$\% 1 \ldots$ & $T \varepsilon$ & $\% 1 \ldots$ & 14 & الاجمال \\
\hline
\end{tabular}

من خلال بيانات الجدول السابق نلاحظ أن:جاء الهدف المرجو من تقديم الموضوعات البيئية فى برنامج بين السما والأرض فى المرتبة الأولى هدف توجيهى ارشادى بنسبة تلاهية

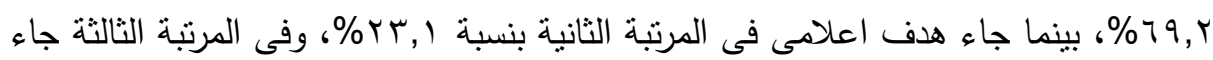
هدف تعلنمى بنسبة \% V,V. Vاء الهدف المرجو من تقديم الموضوعات البيئية فى برنامج البيئة

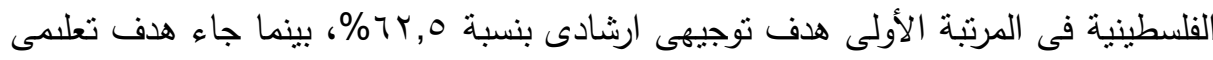

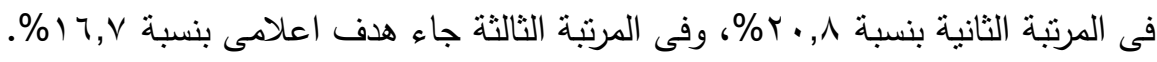
يوضح جدول رقم(• 1): موقع الموضوعات البيئية على مدار الحلقة:

\begin{tabular}{|c|c|c|c|c|}
\hline \multicolumn{2}{|c|}{ البيئة الفلسطينية } & \multicolumn{2}{|c|}{ بين السما والأرض } & \multirow[b]{2}{*}{ موقع الموضوعات } \\
\hline$\%$ & ك5 & $\%$ & كا & \\
\hline$\% \backslash 7, \vee$ & $\varepsilon$ & - & - & في مقدمة الحلقة \\
\hline$\% \wedge, \Gamma$ & r & $\% \vee, \vee$ & 1 & في الوسط الحلقة \\
\hline$\% \vee 0$ & 11 & $\% q r, r$ & TY & على مدار الحلقة \\
\hline$\% 1 \ldots$ & $T \varepsilon$ & $\% 1 \ldots$ & $1 \pi$ & الاجمالى \\
\hline
\end{tabular}

من خلال بيانات الجدول السابق نلاحظ أن:

- - جاء موقع الموضوعات البيئية فى برنامج بين السما والأرض فلى المرتبة الأولى على مدار

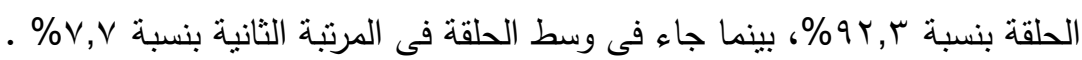
- جاء موقع الموضوعات البيئية فى برنامج البيئة الفلسطينية فى المرتبة الأولى على مدار

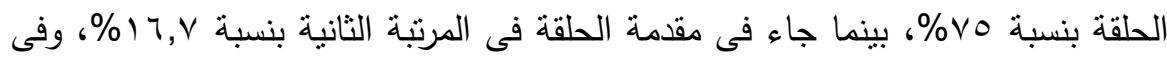

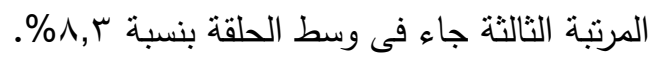


ب: بائج الدراسة الميدانية:

جدول رقم(1 1 ): يوضح مدى الاستماع إلى إذاعة صوت العرب

\begin{tabular}{|c|c|c|c|}
\hline \multirow{2}{*}{ الترتيب } & \multicolumn{2}{|c|}{ الاستجابات } & \multirow{2}{*}{ العبارات } \\
\hline & $(\%)$ & (ك) & \\
\hline 7 & 97,0 & 194 & نع \\
\hline$r$ & $r, 0$ & V & $y$ \\
\hline & $\% 1 \ldots$ & r.. & الإجمالي \\
\hline
\end{tabular}

من خلال بيانات الجدول السابق نستتتج أن:

جاءت نسبة الاستماع إلى صوت العرب في المرتبة الأولى نعم بنسبة ه, 9\%٪، بينما

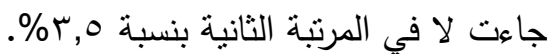
س r - أ) الفروق بين الجنسين ( ذكور - إناث) في مدي الاستماع إلى صوت العرب. جدول رقم(r I): يوضح الفروق بين الجنسين( ذكور - إناث) فيمدي الاستماع إلى صوت

\begin{tabular}{|c|c|c|c|c|}
\hline & & & & العرب \\
\hline \multirow{2}{*}{ الإجمالى } & \multicolumn{2}{|c|}{ النوع } & النسب & مدي الاستماع إلى صوت \\
\hline & إناث & ذكور & والتكرارات & العربّ \\
\hline 194 & 90 & 91 & 5 & \\
\hline$\% 97,0$ & $\% \leqslant \vee, 0$ & $\% \leqslant q$, & $\%$ & سم \\
\hline $\bar{v}$ & 0 & $T$ & 5 & \\
\hline$\% r, 0$ & $\% \curlyvee, 0$ & $\% 1$, & $\%$ & $y$ \\
\hline$r \ldots$ & $1 \ldots$ & $\ldots$ & ك & \\
\hline$\% 1, \cdot$, & $\% 0,$, & $\% \circ,$, & $\%$ & الإجمالى \\
\hline
\end{tabular}
من خلال بيانات الجدول السابق نستنتج أن:

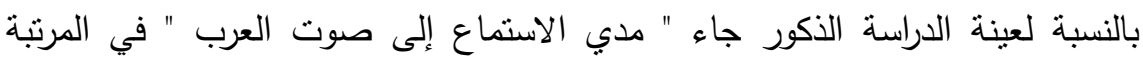

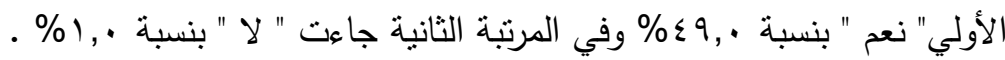

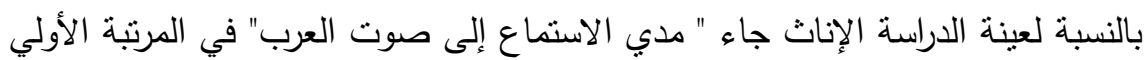

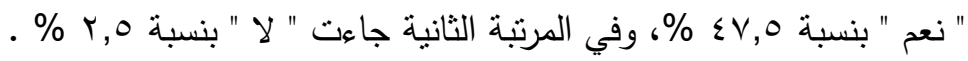


لا توجد فروق ذات دلالة إحصائية بين الجنسين( ذكور - إناث) فى" مدي الاستماع إلى كلى

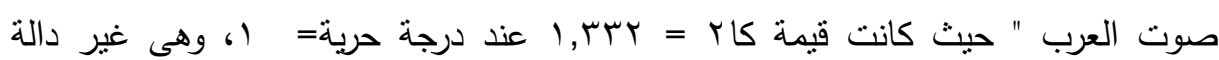

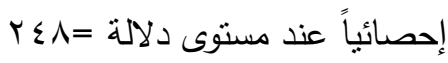

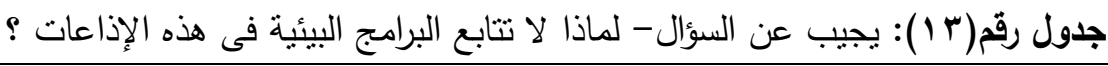

\begin{tabular}{|c|c|c|c|}
\hline \multirow{2}{*}{ الترتيب } & \multicolumn{2}{|c|}{ الاستجابات } & \multirow{2}{*}{ العبارات } \\
\hline & $(\%)$ & (ك) & \\
\hline 1 & $\leqslant \varepsilon$ & $1 \mathrm{~A}$ & لا بناسبني مواعيد تقديمها \\
\hline $\bar{r}$ & 19,0 & $\overline{r q}$ & تقدم المعالجات متحيزة \\
\hline$r$ & $1 \leq$ & rA & لأنها لاتقام ما يفيدنى \\
\hline$\varepsilon$ & $9, \cdot$ & 11 & لا تتنقى ضيوف متخصصين \\
\hline 0 & $\Lambda$, & 17 & أداء المذيعين غير مرضي \\
\hline 7 & 0,0 & 11 & شرحها وتفسيرها غير وافى \\
\hline & $\% 1 \ldots$ & r... & الإجمالّي \\
\hline
\end{tabular}

من خلال بيانات الجدول السابق نستتنج أن: جاءت الإجابة على لماذا لا تتابع البرامج

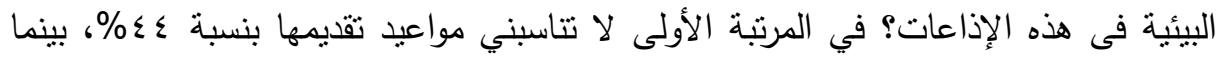

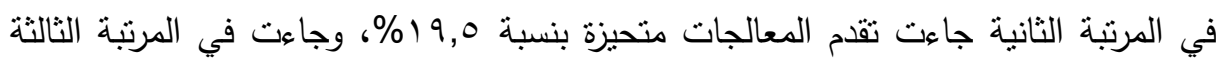

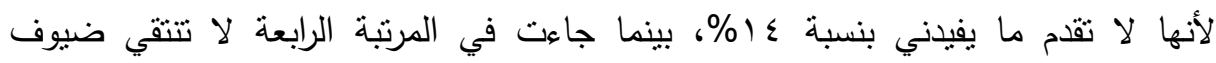
متخصصين بنسبة 9\%، وجاءت في المرتبة الخامسة أداء المذيعين غير مرضى بنسبة هائه \%، بينما جاءت في المرتبة السادسة والأخيرة شرحها وتفسيرها غير وافي بنسبة 0,0٪. 
جدول رقم(ء 1): يوضح الفروق بين الجنسين ( ذكور - إناث) في أسباب عدم متابعة البرامج البيئية فى هذه الإذاعات

\begin{tabular}{|c|c|c|c|c|}
\hline \multirow{2}{*}{ الإجمالى } & \multicolumn{2}{|c|}{ النوع } & \multirow{2}{*}{ والتكرارات } & \multirow{2}{*}{ ألبئيابة في عذم متابعة الإذاعات البرامجج } \\
\hline & إناث & ذكور & & \\
\hline$r \Lambda$ & Ir & 17 & 5) & \multirow{2}{*}{ لانها لا تقدم ما يفيدنى } \\
\hline$\% \backslash \varepsilon$, & $\% 7, \cdot$ & $\% \wedge, \cdot$ & $\%$ & \\
\hline rq & $r$ & 19 & 5 & \multirow{2}{*}{ تقدم المعالجات متحيزة } \\
\hline$\% 19,0$ & $\% 1,$, & $\% 9,0$ & $\%$ & \\
\hline 11 & $\mathrm{~V}$ & 11 & 5 & \multirow{2}{*}{ لانخصصين ت ل } \\
\hline$\% 9, \cdot$ & $\% r, 0$ & $\% 0,0$ & $\%$ & \\
\hline$\Lambda \Lambda$ & $\varepsilon \Lambda$ & $\varepsilon$ & 5 & \multirow{2}{*}{ لا يناسبنى مواعيد تقديمها } \\
\hline$\% \leq \varepsilon$, & \%rE, & \%r., + & $\%$ & \\
\hline 17 & 0 & 11 & 5 & \multirow{2}{*}{ آداء المذيعين غير مرضنى } \\
\hline$\% \wedge, \cdot$ & $\%$ Y,o & $\% 0,0$ & $\%$ & \\
\hline 11 & $\Lambda$ & $r$ & 5 & \multirow{2}{*}{ شرحها وتفسيرها غير وافي } \\
\hline$\% 0,0$ & $\% \varepsilon, \cdot$ & $\% 1,0$ & $\%$ & \\
\hline$r \cdot \cdots$ & $1 \cdots$ & $1 \cdots$ & 5] & \multirow{2}{*}{ 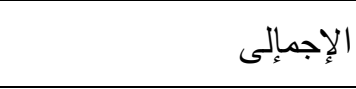 } \\
\hline$\% 1, \ldots$ & $\% 0,, \cdot$ & $\% 0,, \cdot$ & $\%$ & \\
\hline
\end{tabular}
من خلال بيانات الجدول السابق نستنتج أن:

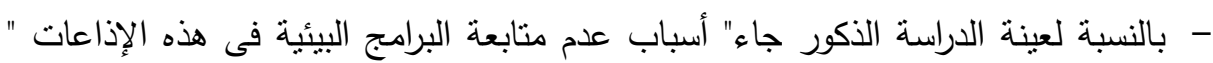

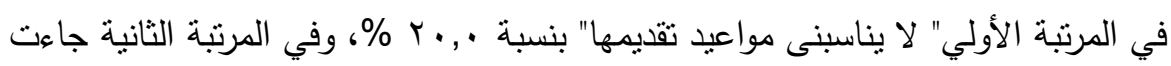

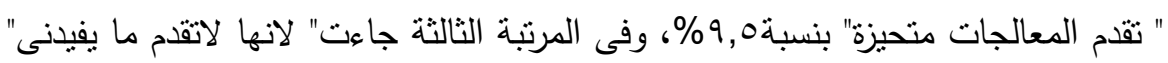

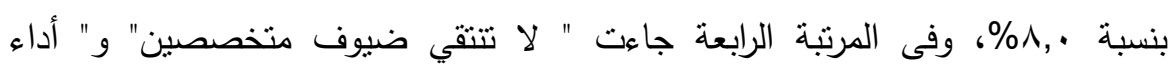
المذيعين غير مرضى" بنسبة 0,0٪، وفى المرتبة الخامسة جاءت" شرحها وتقسيرها غير

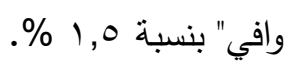

- أما بالنسبة لعينة الدراسة الإناث في المرتبة الأولي جاء" أسباب عدم متابعة البرامج

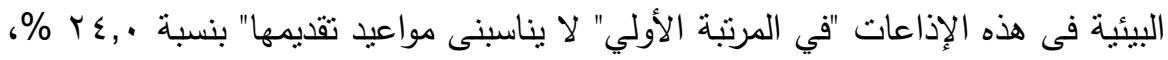

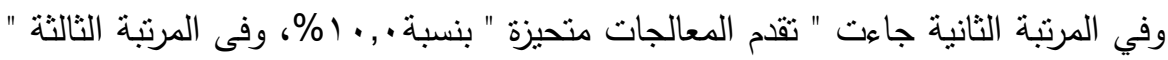

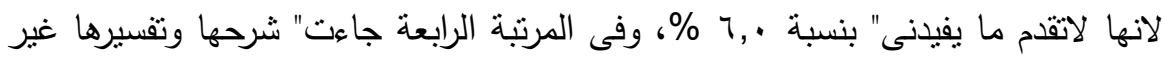


وافي" بنسبة ،, ؛\%، وفى المرتبة الخامسة جاءت" لا نتنقي ضيوف متخصصين" بنسبة

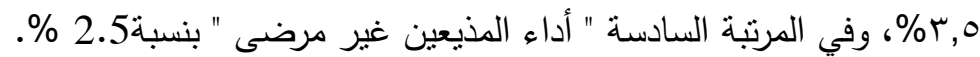

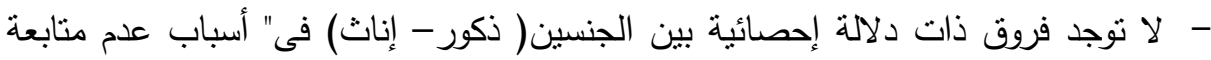

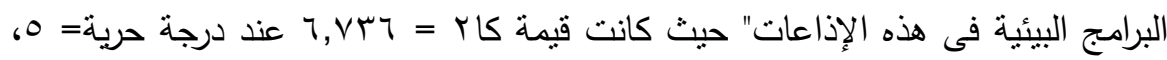

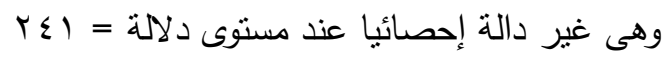
يوضح الجدول(ه 1 ): السبب الأساسى الذى يهدد البقاء الانساني فى عدة مشكلات هو :

\begin{tabular}{|c|c|c|c|}
\hline \multirow{2}{*}{ الترتيب } & \multicolumn{2}{|c|}{ الاستجابات } & \multirow{2}{*}{ العبارات } \\
\hline & $(\%)$ & (5) & \\
\hline r & Y) & $\leqslant 0$ & تعرض البيئية للعديد من المشكلات بفعل الإنسان \\
\hline$r$ & 10,0 & T) & الزيادة الهائلة في عدد السكان \\
\hline$\varepsilon$ & $1 \leqslant, 0$ & rq & الاستتزاف السريع للموارد الطبيعية \\
\hline 1 & ₹9 & 91 & جميع ماسبق \\
\hline & $\% 1 \ldots$ & T.. & الإجمالّي \\
\hline
\end{tabular}

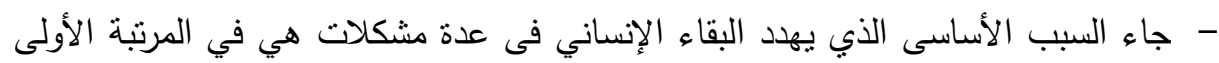

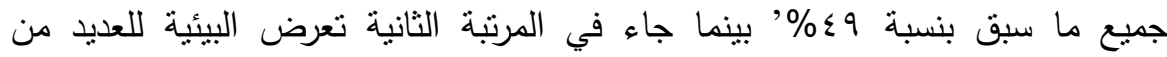

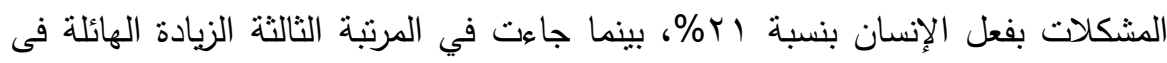

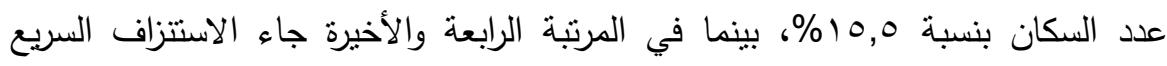

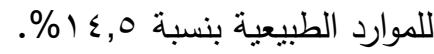
جدول رقم(17 (1): يوضح الفروق بين الجنسين( ذكور - إناث) في السبب الأساسى الذى يهدد

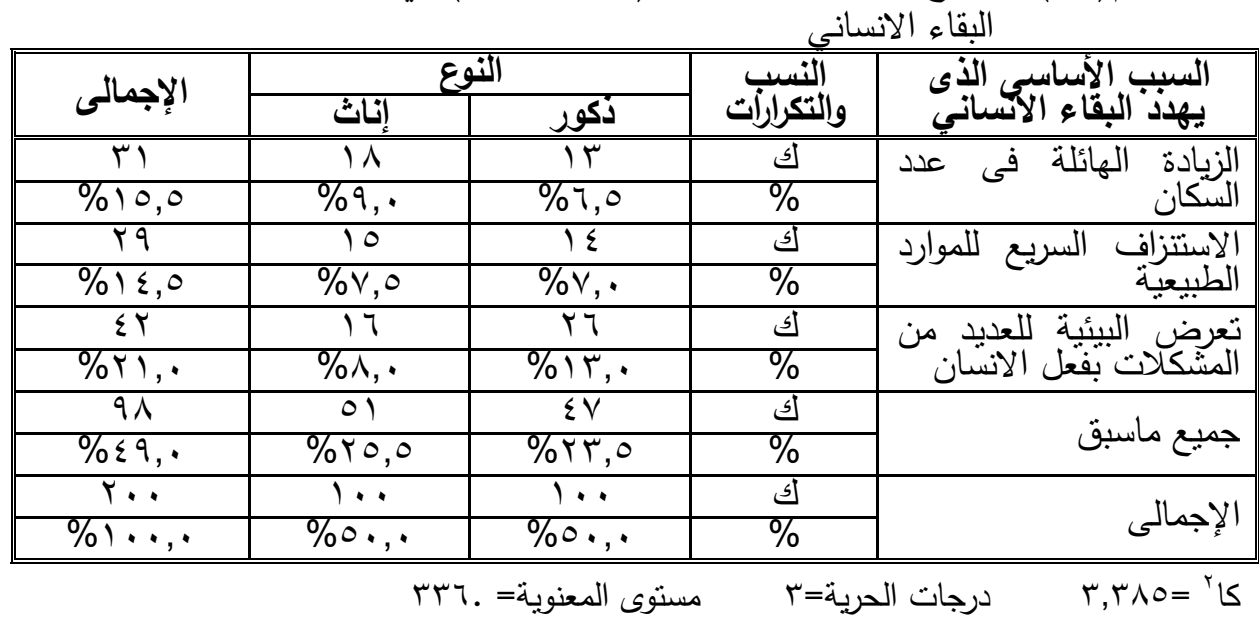


من خلال بيانات الجدول السابق نستتتج أن: - - بالنسبة لعينة الدراسة الذكور جاء " السبب الأساسى الذى يهدد البقاء الانساني" في المرتبة

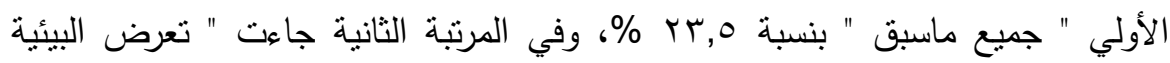

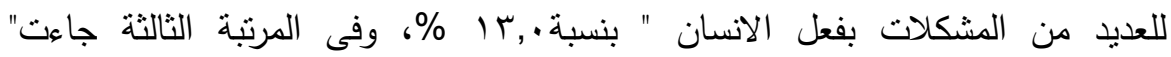

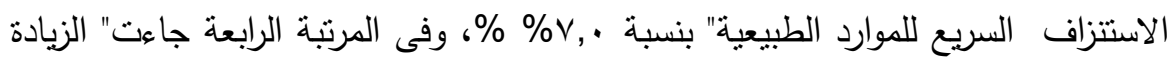

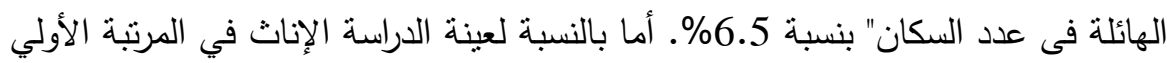

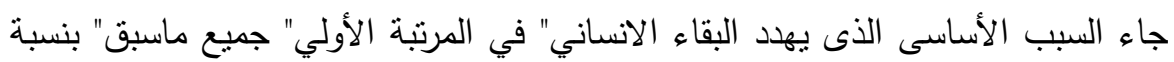

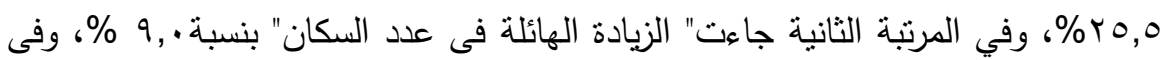

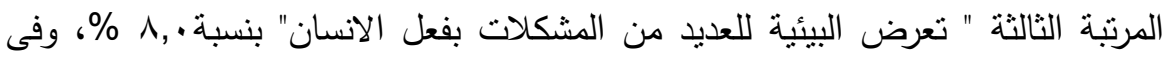

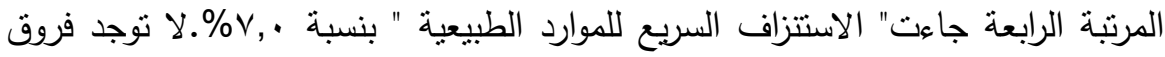

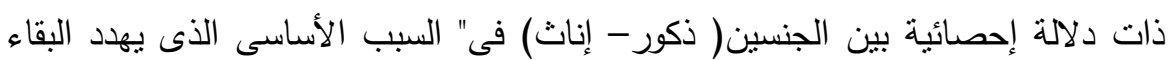

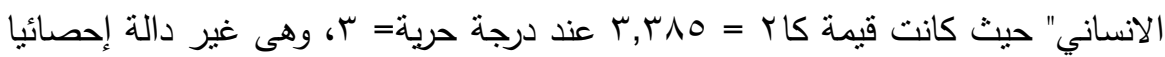

$$
\text { عند مستوى دلالة = بrr. }
$$

يوضح جدول رقم(V V): أسباب الاختلال فى التوازن البيئي؟

\begin{tabular}{|c|c|c|c|}
\hline \multirow{2}{*}{ 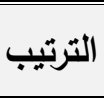 } & \multicolumn{2}{|c|}{ 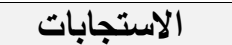 } & \multirow{2}{*}{ العبارات } \\
\hline & $(\%)$ & (5) & \\
\hline 1 & $0 \leqslant$ & $1 \cdot 1$ & تدخل الإنسان المباشر يؤدى إلى إختلال توازن البيئية \\
\hline$r$ & YI, & $\sum Y$ & تغير الظروف الطبيعية يؤثر سلباًة على مواردها \\
\hline r & 17,0 & r & ألبيئيب كائن حي فى بيئة جديدة يؤدى إلى اختلال التوازن \\
\hline$\varepsilon$ & $\Lambda, 0$ & IV & زيادة عدد سكان الكرة الأرضية لاينقص من مواردها \\
\hline & $\% 1 \ldots$ & Y... & 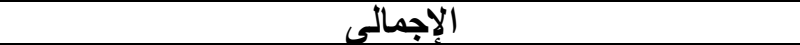 \\
\hline
\end{tabular}

- من خلال بيانات الجدول السابق نستتنج أن:جاء الإخلال في التوازن البيئي ينتج عن في

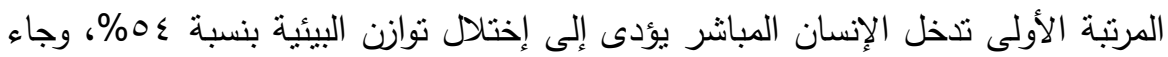

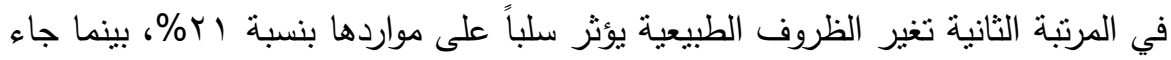
في المرتبة الثالثة إدخال كائن حي فى بيئة جديدة يؤدى إلى إختلال التوازن البيائيى بنسبة لونية 
1,0 1\%، وفي المرنبة الرابعة والأخيرة جاء زيادة عدد سكان الكرة الأرضية لاينقص من

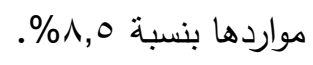

\section{الميوكياهي}

ا-ضرورة دمج البرامج البيئية مع البرامج الإذاعية الأخرى المنوعات والثقافية والدينية

$$
\text { والاجتماعية. }
$$

r - لابد من الاهتمام بالبرامج البيئية على الثبكات الإذاعية الاخرى باعتبارها من أهم دعائم

$$
\text { الامن البيئي. }
$$

r- ازدياد محاولة التوعية بالمشكلات البيئية عن طريق وسائل الاعلام المختلفة، والمؤتمرات

$$
\text { والندوات بصورة مستمرة. }
$$

ع-تضمين البرامج البيئية فى الأشكال الإذاعية الأخرى(الدراما- برامج المنوعات- البرامج

$$
\text { الثقافية- برامج المسابقات ) }
$$

$$
\text { ه-تنبى الإذاعة المصرية حملات لتتمية المسئولية البيئية وزيادة الوعي البيئى. }
$$

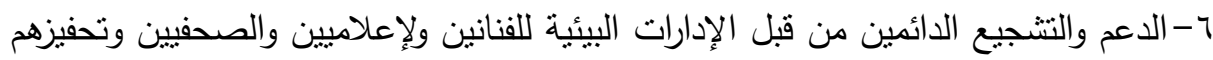

للإبداع في الطرح البيئي، وتوفير قواعد البيانات ومصادر للمعلومات البيئية وتعيين جهة البدات والين

مسئوله لايها ألقدره على إيصال المعلومة البيئية بشكل جيد مدعومة بالأرقام والبيانات.

V-توعية شاغلي المناصب العلا الإعلامية بأهمية الدور الذي يقومون به للحفاظ على البيئة

$$
\text { والمساهمة في استمرارية التتمية المستدامة بالوطن. }
$$

^-التخطيط الإعلامي المسبق للأهداف المرجوة من الطرح الإعلامي البيئي لما يخدم

$$
\text { المصالح العليا للوطن وبعيداً عن الإثارة غير المبررة. }
$$

9-تبادل الخبرات المكتسبة في مجال التوعية والإعلام البيئي بين الجهات المسؤولة عن النيرة التوعية والإعلام البيئي في القطاعين الحكومي والخاص لصقل وتتمية مهارات القائمين

$$
\text { على الإعلام البيئي. }
$$

• 1 - منح المجتمع وعلى جميع مستوياته الفرص في تحمل مسئوليته بالمشاركة في طرح رأيه

البيئي عبر القنوات الإعلامية لتكون وسيلة إيداعية تفاعلدة لنشر الوعي والتقافة البيئية. 


\section{zall}

التربية فى مواجهة مشكلات البيئة مجلة التربية الجديدة العدد السابع عشر، اليونسكو

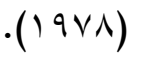

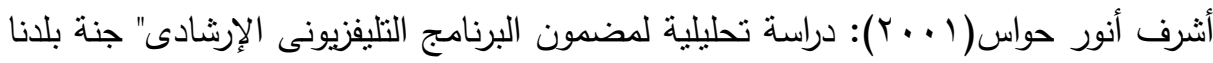

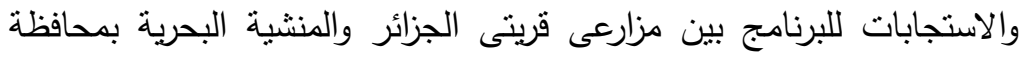

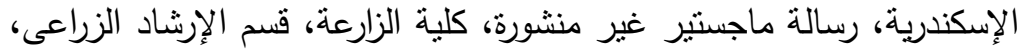

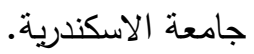

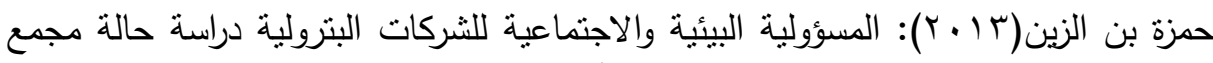

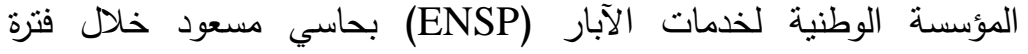

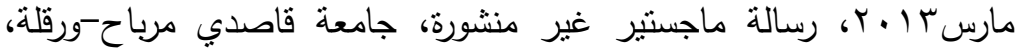

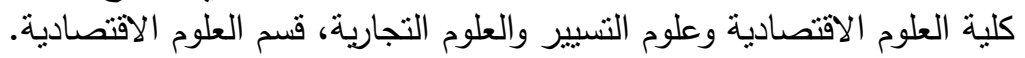

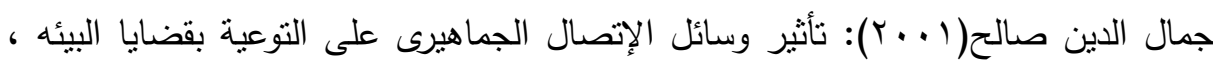

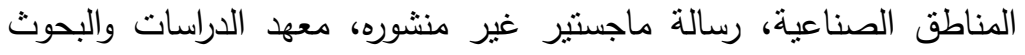
البيئية، جامعة عين شمس.

جيهان رشتى(ب99 (19): الاعلام ودوره فى تغيير السلوك تجاة قضايا البيئية ندوة الاعلام

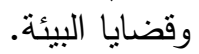

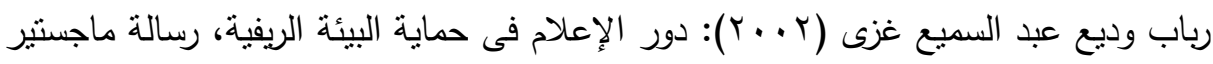
غير منشورة، قسم الإرشاد الزراعى، كلية الزراعة، جامعة المنصورة.

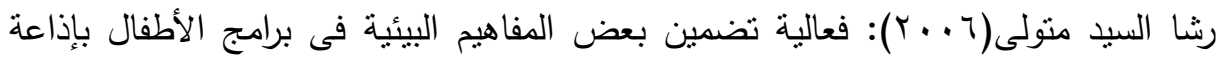

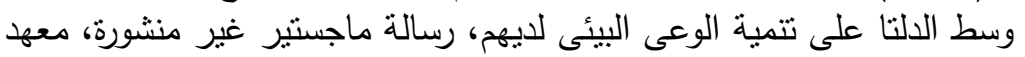
الدراسات والبحوث البيئية، قسم التربية والثقافه البيئية، جامعة عين شمس.

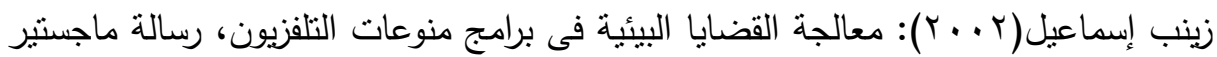
غير منشوره، معهز الدراسات والبحوث البيئيه، قسم التربيه والنقافة البيئية،

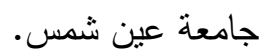

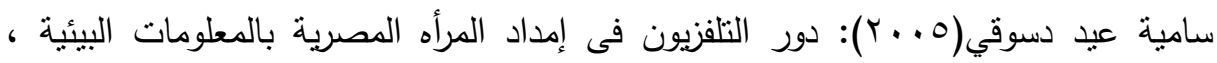

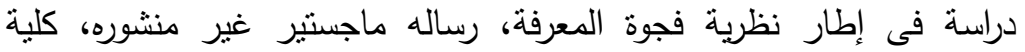
الإعلام، قسم الإذاعة والتلفزيون، جامعة القاهرة. 


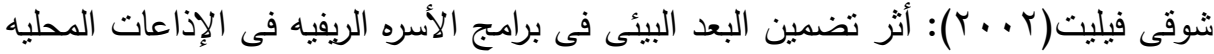

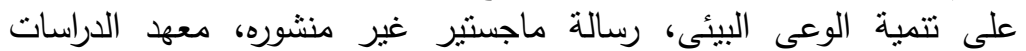
والبحوث البيئية، قسم التربية والثقافة البيئية، جامعة عين شمس.

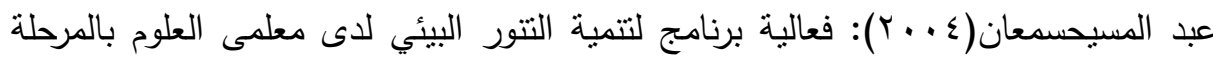

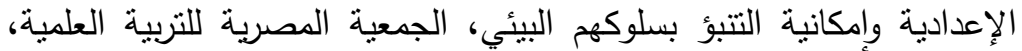

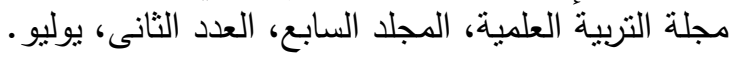

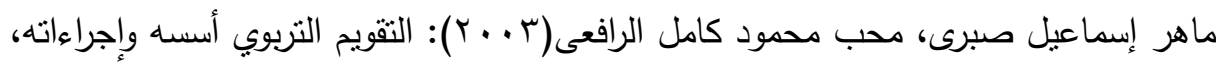
طء، مكتبة الرشد للنشر والتوزيع، الرياض.

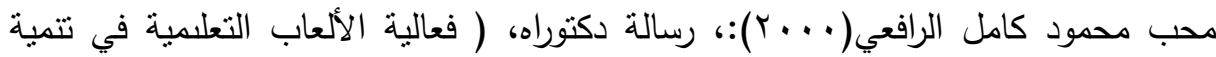

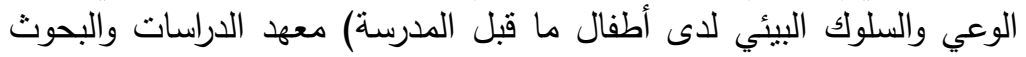

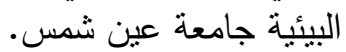

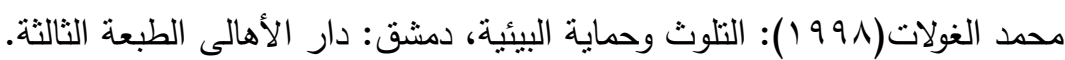
محي الدين صابر(9^v(I): الاعلام البيئى دراسة ونماذج،تونس المنظمة العربية للتربية والثقافة والعلوم. (19) الان.

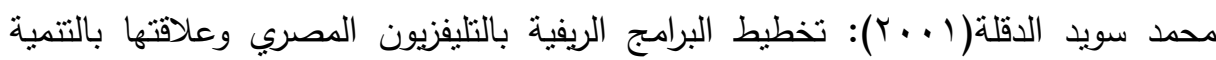

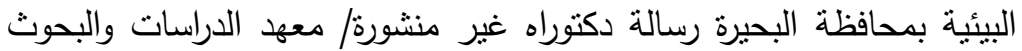

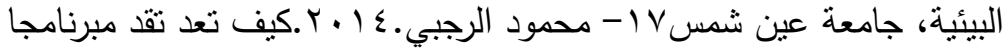
تلفزيونيا.عمان: مؤسسة الفرسان للنشر والتنوزيع.

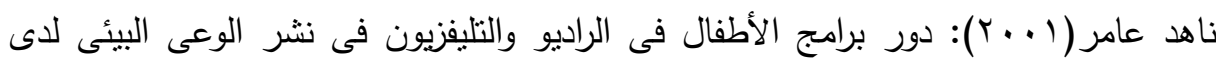

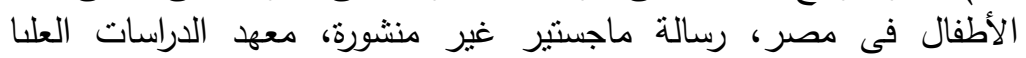
للطفولة، جامعة عين شمس، القاهرة. 
محمود حسن اسماعيل وآخرون

\title{
AN ANALYTICAL STUDY FOR TREATING THE ENVIRONMENT'S ISSUES IN ENVIRONMENTAL PROGRAMS OF SOT EL-ARAB BROADCASTING NETWORK
}

\author{
Ismail, M. H. ${ }^{(1)}$; Shalbey, A. I. ${ }^{(2)}$ and Ismail, A. M. ${ }^{(3)}$ \\ 1) Institute of Post Graduate Childhood Studies, Ain Shams University. \\ 2) Faculty of Education, Ain Shams University 3) BBC \& Radio \& \\ Television Union
}

\begin{abstract}
The research aimed at identifying the role of Sot El Arab Broadcasting by its three broadcasts (Sot El Arab- Ezaet PalastineWady El Nile Broadcast) tackled what is meant by the development of environmental responsibility, its elements and the role of "Sot El Arab Broadcasting" in its development, it also used form content analysis of the environment programme at "Sot El Arab Broadcasting" and a questionnaire for applying a specific sample of 200 students aging between (18-21) years from Cairo and Ain Shams University during 2015.

This research content analysis concluded the following:

1. There is a direct correlation between the amount of exposure to environment programs and the increasing of environmental awareness for respondents.

2. In each edition of "Between Heaven and Earth" (been es-samma welard), every topic of the environmental topics (definitions, reasons, impact and solutions) were tackled, while in the program of "The Palestinian environment" (Albee'a alfalasteenya) every topic was tackled separately. In the first place came "showing the impact" with $36 \%$, followed by "introducing the reasons" with $32 \%$. In the third
\end{abstract}

$$
\text { المجلا الثالث والثثلاثون، الجزء الثاني، يونيو } 17 \text { ـ ب r }
$$




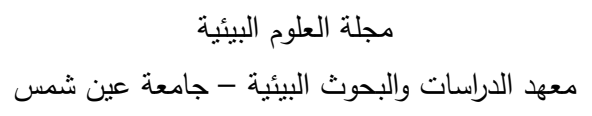

place came "definition of problems" and finally "presenting solutions" with $14 \%$ in all its editions.

3. The style of introducing the environmental topics in "The Palestinian environment" (Albee'a alfalasteenya) came as following: introducing the topic and encouraging the audience to practice a positive environmental behavior with $54.2 \%$, introducing the issue and its solution with $25 \%$ and introducing the topic with only $20.8 \%$.

4. The used Radio genres in introducing the environment programs came as following: in "Between Heaven and Earth" (been es-samma wel-ard) the interview genre was used, while "The Palestinian environment" (Albee'a alfalasteenya) came as a narration program.

5. The response for the inquiry: "Do you follow environment programs on "Soot elarab Broadcasting network"?" was "No" with $52.3 \%$ and "Yes" with $47.7 \%$.

6. The response for the inquiry: "Do you think that environment programs on these Radio networks present useful information?" was "Yes" with $90 \%$ and "No" with $10 \%$.

7. As for the response for: "Why do you not follow environmental programs on these Radio networks?", the reasons came as following: the first was "Airing time is not suitable for me" with $43 \%$, the second was "they present biased solutions" with $18.7 \%$. The third reason was "they do not offer useful information for me" with $15 \%$, while in the fourth was "they do not interview specialists as their guests" with 9\%. Finally came "the performance of the announcers" as the fifth reason with $8.3 \%$ and the last one was "providing unsatisfying presentations of the topics" with $6 \%$.

8. Taking an example like "Sea pollution", the survey showed the reasons behind it as following: the first reason was "connecting the sewage system with the sea" with $80 \%$, "sea life waste" with $8.7 \%$, "increased salinity of seawater" with $8.3 \%$ and finally "heavy raining" with only $3 \%$. 